\title{
Landslide susceptibility evaluation and hazard zonation techniques - a review
}

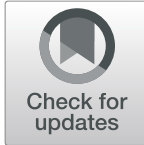

Leulalem Shano ${ }^{1 *}$, Tarun Kumar Raghuvanshi ${ }^{2}$ and Matebie Meten ${ }^{3}$

\begin{abstract}
Landslides are the most destructive geological hazard in the hilly regions. For systematic landslide mitigation and management, landslide evaluation and hazard zonation is required. Over the past few decades several techniques have been developed that can be used for landslide evaluation and zonation. These techniques can broadly be classified into qualitative and quantitative approaches. Qualitative approaches include geomorphological analysis and heuristic techniques whereas quantitative approaches include statistical, artificial intelligence and deterministic techniques. In quantitative techniques prediction for landslide susceptibility is based on the actual realistic data and interpretations. Further, the quantitative techniques also overcome the subjectivity of qualitative approaches. Each of these techniques may consider different causative factors and utilizes various means for factor evaluation and analysis. When compared, each of these techniques has its own advantage and disadvantage over other techniques. The selection of appropriate technique for landslide hazard evaluation and zonation is very crucial. The factors that need to be considered to adopt an appropriate approach are; investigation purpose, the extent of the area to be covered, the type of mapping units, the scale of map to be produced, type of data to be used, type of landslides, availability of resources, capability and skill set of an evaluator and the accessibility to the study area. The main aim of this article is to present a comprehensive review on various techniques and approaches available for landslide susceptibility and hazard zonation mapping. Further, attempt is also made to assess the effectiveness of these techniques in landslide hazard zonation studies.
\end{abstract}

Keywords: Landslide, Landslide susceptibility, Landslide evaluation, Landslide zonation

\section{Introduction}

Landslides are considered to be the most damaging geological hazard in mountainous regions (Mengistu et al. 2019; Hamza and Raghuvanshi 2017; Girma et al. 2015; Raghuvanshi et al. 2014a; Pan et al. 2008; Kanungo et al. 2006; Crozier and Glade 2005; Dai et al. 2002; Parise and Jibson 2000; Varnes 1996). In the landslide study there are three basic components, these are landslide susceptibility, landslide hazard and landslide risk. Landslide susceptibility mapping or zonation is the subdivision of the terrain in to zones that have a different likelihood for landslide occurrence. It includes spatial distribution, size, location and displacement of the

\footnotetext{
* Correspondence: leulalemshano@gmail.com

${ }^{1}$ Department of Geology, College of Natural Sciences, Arba Minch University, Arba Minch, Ethiopia

Full list of author information is available at the end of the article
}

landslide deposit (Fell et al. 2008; Guzzetti et al. 1999; Varnes 1984). Landslide hazard mapping/zonation is a division of terrain into zones that are basically characterized by the spatial and temporal probability of landslide occurrence that includes description of location, volume, and prediction of future landslide occurrence in an area (Fell et al. 2008; Fell et al. 2007; AGS 2000).

In order to minimize the damage due to landslides it is necessary to evaluate the factors that are responsible for the landslides. These factors are related to geology, geomorphology, landuse and landcover, rainfall, seismicity, manmade activities etc. (Raghuvanshi et al. 2014a; Anbalagan 1992). For landslide studies it is generally assumed that the combination of these factors may possibly lead to landslides in a given area. Therefore, evaluation of these factors and their relation with the past landslides in an area may form the basis for the 
prediction of future landslides (Chimidi et al. 2017; Negassa and Kala 2015; Girma et al. 2015).

In order to evaluate and zone the area for potential landslides, landslide hazard evaluation and zonation techniques may be applied (Hamza and Raghuvanshi 2017; Girma et al. 2015; Raghuvanshi et al. 2014a; Bisson et al. 2014; Pan et al. 2008; Anbalagan 1992). In past several techniques have been developed by various researchers that can broadly be classified into inventory based approaches, expert evaluation (Raghuvanshi et al. 2014a; Guzzetti et al. 1999; Turrini and Visintainer 1998; Sarkar et al. 1995; Anbalagan 1992; Pachauri and Pant 1992 etc.), statistical (Negassa and Kala 2015; Girma et al. 2015; Kanungo et al. 2006; Dai and Lee 2001; Carrara et al. 1992 etc.), deterministic (Fall et al. 2006), probabilistic and distribution free approaches (Kanungo et al. 2006). Several studies have attempted to list and review the techniques those are applied for landslide susceptibility and hazard zonation (Lee 2015; Thiebes et al. 2012; Michoud et al. 2012; Jaboyedoff et al. 2012; Jongmans and Garambois 2007; Angeli et al. 2000; Turner and Schuster 1996, etc.). Each of these techniques considers various factors and uses different means for factor evaluation and analysis. When compared, each of these techniques have its own characteristics and may have certain advantage and disadvantage over the other techniques (Raghuvanshi et al. 2014a; Fall et al. 2006; Kanungo et al. 2006; Casagli et al. 2004; Guzzetti et al. 1999; Leroi 1997). Further, some degree of uncertainty always exists in these techniques owing to factors that are considered or the methods that are followed to generate the factor data (Negassa and Kala 2015; Carrara et al. 1995).

Further, these landslide hazard techniques can be applied at different scales depending on the area to be covered, the geological and geo-morphological factors to be considered, the methods by which the concerned factor data will be generated and the capability and skill set of an evaluator (Ermias et al. 2017; Chimidi et al. 2017; Fall et al. 2006; Kanungo et al. 2006; Casagli et al. 2004; Guzzetti et al. 1999; Leroi 1997; Carrara et al. 1992). The main objective of the present research work is to present a comprehensive review on various techniques and approaches that are available for landslide susceptibility and hazard zonation mapping. Further, it is also attempted to assess the effectiveness of these techniques in landslide hazard zonation studies.

\section{Data types and software for landslide studies}

Data collected from the field visit and/or remote sensing image analyses are the initial steps for landslide studies. The technique, by which data pertaining to landslide study is generated, primarily depends on the scale of the study, purpose of the study and the accessibility to the study area. The data that is needed for landslide susceptibility and hazard zonation studies mainly includes data on; landslide inventory, environmental and triggering factors (Sreedevi and Yarrakula 2016; Metternicht et al. 2005; Soeters and Van Westen 1996). The environmental factors mainly consist of slope angle, slope aspect, flow accumulation, lithology, geological structures/ proximity to faults, soil type, soil depth/ thickness, slope hydrology, geomorphology, proximity to streams, road cuts, land use types and changes etc. The triggering factors include daily rainfall, rainfall intensity/ duration, earthquake and volcanic eruption. In general, it is not possible to define a uniform list of such causal factors that would be required for the landslide studies. The selection of such causal factors may differ, depending on the scale of analysis, the characteristics of the study area, the landslide type, and on the failure mechanisms. The main difference between the data collection for landslide susceptibility and hazard zonation is in the collection of landslide inventory data; for landslide hazard spatial and temporal landslide data from archive, image analysis etc. is required whereas for landslide susceptibility only spatial data is sufficient. Further, based on the type of the selected technique, the data listed above is changed either in to grid cell, terrain units, uniquecondition units, slope units or in to topographic units (Reichenbach et al. 2018; Guzzetti et al. 1999).

The commonly used software for landslide studies are ArcGIS package that is used for mapping landslide influenced area, factor maps preparation, overlay analysis and interpretations. Erdas Imagine is used for image processing that allows processing for geospatial factor layers used for landslide susceptibility and hazard studies. Further, Geostudio, Geoslope's and SLOPE/W are used for geotechnical slope stability studies. Also, SPSS/real statistics and MS Excel are used for data management and statistical analysis.

\section{Methods of landslide susceptibility and hazard zonation}

In order to evaluate landslide susceptibility and hazard zonation several approaches and techniques have been proposed. These includes landslide inventories, heuristic terrain and susceptibility zoning, statistical methods, deterministic methods, probabilistic methods etc. (Reichenbach et al. 2018; Corominas et al. 2014; Raghuvanshi et al. 2014a; Negassa and Kala 2015; Kanungo et al. 2006; Aleotti and Chowdhury 1999; Guzzetti et al. 1999). Broadly, all these techniques or approaches may be further classified into qualitative and quantitative approaches (Fig. 1). The qualitative approaches include distribution analysis or inventory, geomorphic analysis and the expert (heuristic) evaluation techniques which are based on the knowledge and experience of the 


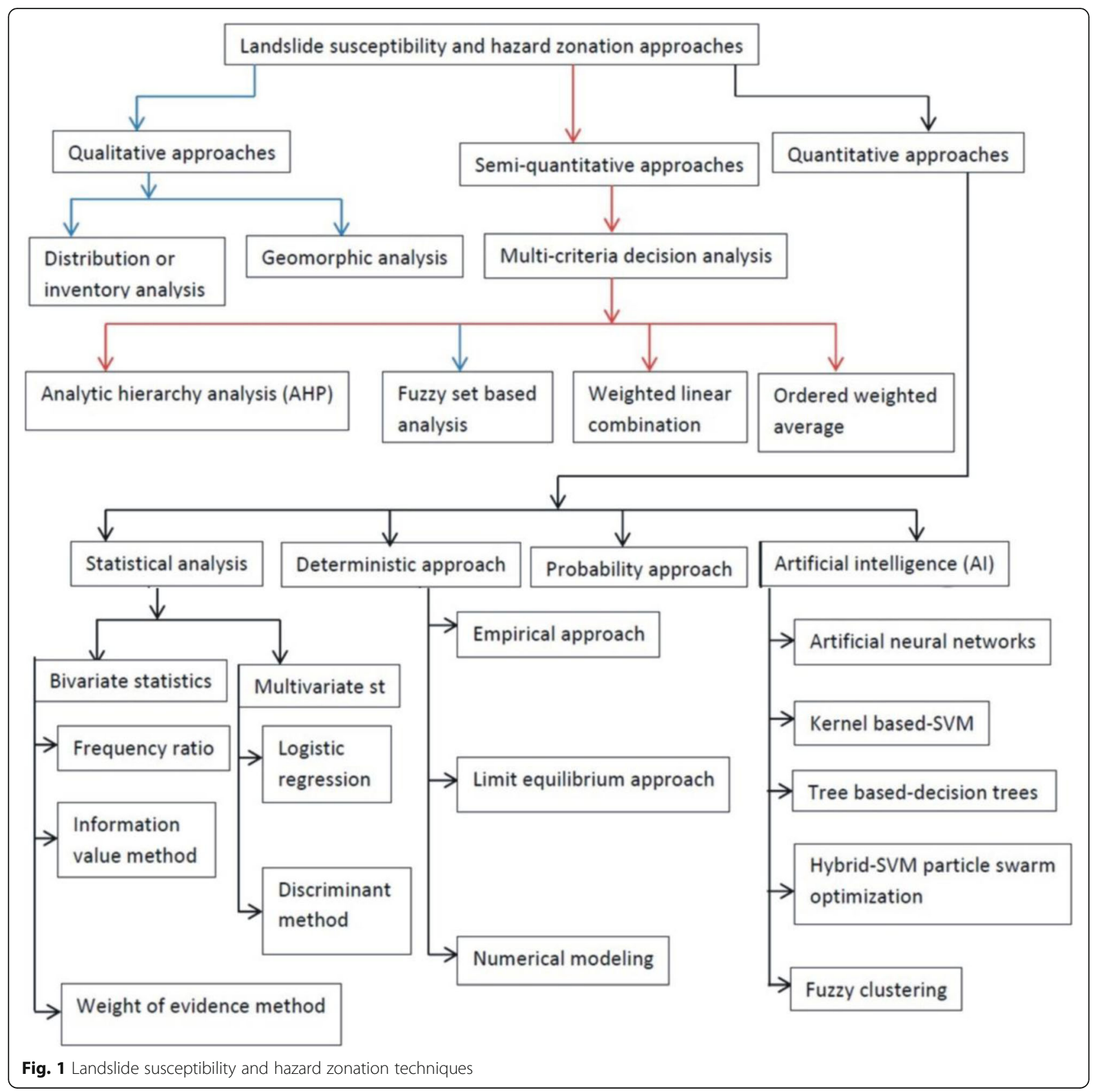

evaluator (Corominas et al. 2014; Raghuvanshi et al. 2014a). The quantitative approaches mainly include statistical, deterministic, probabilistic and distribution free techniques (Raghuvanshi et al. 2014a; Kanungo et al. 2006). The qualitative approaches are considered to be subjective in nature (Girma et al. 2015; Raghuvanshi et al. 2014a; Kanungo et al. 2006; Fall et al. 2006; Casagli et al. 2004) whereas quantitative approaches are considered to be objective in nature (Girma et al. 2015; Fall et al. 2006). In recent times quantitative approaches have been widely used for landslide susceptibility and hazard evaluation.
Direct approaches

\section{Geomorphic and landslide inventory techniques}

The geomorphic techniques are the direct methods of landslide susceptibility and hazard zonation mapping. Most of the data pertaining to various factors responsible for landslides are obtained through remote sensing and the data procurement from direct field work is rarely employed in these methods. The geomorphic mapping of landslides susceptibility is carried out through aerial photographs (Mandaglio et al. 2016; Kanungo et al. 2009; Guzzetti et al. 1999; Verstappen 1983) or from satellite images (Nossin 1989). These 
methods most commonly, but not necessarily are associated with the production of a landslide inventory map.

Landslide inventory includes mapping of the past landslides in the area. This method also includes collection and recording of data on location, type and dimensions of landslides. Beside, data/ information on responsible causative factors, triggering mechanism and landslides occurrence frequency is also collected (Girma et al. 2015; Fall et al. 2006; Dai et al. 2002; Dai and Lee 2001). Landslide inventory mapping is considered to be straight forward and is required for most of the susceptibility and hazard zonation techniques (Dai and Lee 2002) either to formulate the general rules for the hazard prediction or to validate the predicted model. Generally, these geomorphic techniques do not consider the factors that have initiated or triggered the landslides. The principal factors that are considered for landslide hazard zonation are lithology, geomorphology, landuse and landcover and presence or absence of landslides in the area.

\section{Indirect approaches \\ Expert evaluation}

These techniques are indirect method of landslide evaluation and zonation. These techniques are based on various causative factors that are selected by the evaluator. In these techniques expert makes a decision on the degree and type of hazard for the given area, for which he may use either an indirect or a direct mapping approach. The landslide hazard is evaluated based on quasi-static variables (Fall et al. 2006; Dai and Lee 2001) which are primarily based on the judgment and experience of an evaluator (Girma et al. 2015; Raghuvanshi et al. 2014a; Fell et al. 2008; Gorsevski et al. 2003; Guzzetti et al. 1999; Aleotti and Chowdhury 1999; Van Westen et al. 1997; Soeters and Van Westen 1996; Varnes and IAEG 1984; Carrara et al. 1995; Hutchinson 1995). Since these methods are based on the evaluation of an expert therefore they are considered to be subjective in nature (Girma et al. 2015; Ruff and Czurda 2008; Kanungo et al. 2006; Fall et al. 2006; Casagli et al. 2004).

The landslide susceptibility and hazard evaluated by heuristic technique for a given area may vary considerably if evaluated by different experts. However, these techniques are popular because of their simplicity in application. These techniques are based on data, primarily acquired from the field and are well supported by the judgment and experience of an evaluator (Raghuvanshi et al. 2014a, 2014b). Some examples of expert evaluation techniques are; techniques proposed by Raghuvanshi et al. (2014a), Ayenew and Barbieri (2005), Guzzetti et al. (1999), Turrini and Visintainer (1998), Sarkar et al. (1995), Anbalagan (1992), Pachauri and Pant (1992) etc.

\section{Multi-criteria decision analysis methods}

These methods are semi-quantitative approaches which are mostly used for landslide susceptibility evaluation (Abija et al. 2020; Erener et al. 2016; Ahmed 2015; Feizizadeh et al. 2014; Kavzoglu et al. 2013; Feizizadeh and Blaschke 2012; Gorsevski and Jankowski 2010) and hazard zonation studies (Bera et al. 2019). The methods which are categorized under multi-criteria decision analysis are analytical hierarchy process (AHP), fuzzy set based analysis, weighted linear combination and ordered weighted average (Bera et al. 2019; Ahmed 2015; Feizizadeh and Blaschke, 2012). Recently to minimize the subjectivity during factors weighting fuzzy linguistic based approaches are also being used. Some aforementioned subgroups of multi-criteria decision methods are discussed in the following paragraphs. These are AHP, the concept of fuzzy logic and weighted overlay method.

Analytic hierarchy process (AHP) approach The AHP is a multi-criteria decision making approach which is utilized to evaluate the landslide hazard susceptibility and hazard zonation mapping. It is a systematic approach that involves problem definition, goals and alternatives determination, formulation of pair wise comparison matrix, weight determination and finding an overall priority (Pardeshi et al. 2013; Saaty 2008). Landslide is a complex process that is resulted by combination of various causative factors (Raghuvanshi, 2019; Chimidi et al. 2017). The AHP approach can be applied in absolute or a relative measurement of relationship between causative factors and landslides. In absolute measurement each alternative is compared with one ideal alternative whereas, in relative measurement each alternative is compared with many other alternatives. The absolute measurement approach is normative that is conditioned by what is known to be the best. In contrast, the relative measurement approach is conditioned by the experience and ability to judge observations by an evaluator thus, it is descriptive in nature (Pardeshi et al. 2013; Saaty and Vargas 2006; Saaty 2008). Each of the landslide causative factors can be taken as alternatives. Further, these causative factors are assigned with absolute numbers (1-9) based on their relative significance in inducing instability to the slope (Yagi 2003). Thus, comparison matrices are developed to determine Consistency Ratio (CR) and Consistency Index (CI) (Pardeshi et al. 2013).

Weighted overlay method Weighted overlay method is a simple and direct method that can be used for the evaluation of landslide hazard in the given area (Ayele et al. 2014; Erener and Duzgun 2012; Bachri and Shresta 
2010; Intarawichian and Dasananda 2010). This method is based on the assumption that the conditions that has resulted into the past landslides if reoccur in future in other areas, again landslides can occur. In weighted overlay method, for each considered causative factor layers, every cell is reclassified based on the preferred scale as per the significance with respect to the contribution that particular factor class can have on landslide occurrence. Such preferred scale is generally taken from 1 to 9 with 9 being the most significant with respect to the landslide occurrence. Thus, all causative factor layers are combined in GIS environment by using Weighted Overlay Model equation (Eq. 1). Besides, respective weights are also assigned to the causative factors on $0-9$ ordinal scale. The numeric numbers assigned to factor class are termed as ratings and the numbers assigned to respective causative factors are known as weight (Kanungo et al. 2006; Lee et al. 2004). The higher weight or rating to a causative factor or to its respective class represents its greater significance for landslide occurrence (Ayele et al. 2014; Kanungo et al. 2006).

$$
S=\frac{\sum W_{i} S_{i j}}{\sum W_{i}}
$$

Where; ' $\mathrm{W}_{\mathrm{i}}$ ' is the weight of ith factor map, ' $\mathrm{S}_{\mathrm{ij}}$ ' is the ith spatial class weight of ' $\mathrm{jth}$ ' factor map, ' $\mathrm{S}$ ' is the spatial unit value in output map.

Fuzzy logic method The processes, events or function that change continuously may possibly be un-defined in terms of true or false events, thus these events or activities are expressed in fuzzy manner. The things which are vague or not clear are known as fuzzy. The Fuzzy logic is considered to be a superset of Boolean logic which is a extension to address partial truth values that are completely false or completely true (Lee 2007; Chacón et al. 2006; Gorsevski et al. 2003). Fuzzy logic method is applied in landslide studies to avoid subjectivity owing to selection of various multiple causative factors (Meten et al. 2015; Chacón et al. 2006; Zadeh 1978). The Fuzzy logic method is based on the fuzzy set theory in which membership degrees of elements can have varying degrees of confidence in an interval of [0, 1] (Ross 2010; Lee 2007; Kanungo et al. 2006). There are various fuzzy operators that can be used, these are; 'fuzzy or', 'fuzzy and', 'fuzzy algebraic product', 'fuzzy algebraic sum' and 'gamma operator'.

Among these, 'fuzzy and' has equivalence with 'Boolean AND' (logical intersection) operation in values of classical set (Razifard et al. 2018; Anbalagan et al. 2015; Lee 2007) (Eq. 2).

$$
\mu_{\text {Combination }}=\operatorname{MIN}\left(\mu_{A}, \mu_{\mathrm{B}}, \mu_{C} \ldots .\right)
$$

Where ' $\mu_{\text {Combination' }}$ is the fuzzy membership function, ' $\mu_{\mathrm{A}}$ ' represents the membership value of map ' $\mathrm{A}$ ' at specified location, and ' $\mu_{\mathrm{B}}$ ' represents the value of map ' $\mathrm{B}$ ' at specified location, likewise ' $\mu_{C}$ ' and so on.

Similarly, the 'fuzzy or' is equivalent to 'Boolean OR' (logical union) that represents the values of output membership, controlled by the maximum values for any of the input maps. Thus, the 'fuzzy or' can be represented as (Lee 2007; Zimmermann 1996) (Eq. 3):

$$
\mu_{\text {Combination }}=\operatorname{MAX}\left(\mu_{A}, \mu_{B}, \mu_{C} \ldots .\right)
$$

Further, the 'fuzzy algebraic product' operator can be expressed as (Zimmermann 1996; Bonham-Carter 1994) Eq.4;

$$
\mu_{\text {Combination }}=\prod_{i=1}^{n} \mu i
$$

Where; ' $\mu_{\mathrm{i}}$ ' represents the fuzzy membership function for the ' $\mathrm{i}$ 't ' map and ' $\mathrm{i}$ ' represents $1,2 \ldots \mathrm{n}$ maps that are to be combined.

Similarly, the 'fuzzy algebraic sum' compliments to 'fuzzy algebraic product' and is expressed as (Lee 2007; Zimmermann 1996; Bonham-Carter 1994) (Eq. 5);

$$
\mu_{\text {Combination }}=1-\prod_{i=1}^{n}(1-\mu i)
$$

Where; ' $\mu_{\mathrm{i}}$ ' represents the fuzzy membership function for the ' $\mathrm{i}$ 'th' map and ' $\mathrm{i}$ ' represents $1,2 \ldots \mathrm{n}$ maps that are to be combined.

Finally, the 'gamma operation' can be expressed in terms of the 'fuzzy algebraic product' and the 'fuzzy algebraic sum' as (Anbalagan et al. 2015; Zimmermann 1996; Bonham-Carter 1994) (Eq. 6)

$$
\mu_{\text {Combination }}=(\text { Fuzzy algebric sum })^{\lambda} *(\text { Fuzzy algebric product })^{1-\lambda}
$$

Where; ' $\lambda$ 'express a parameter that is chosen in the range of $(0,1)$, the fuzzy algebraic sum is calculated through Eq. 5 and fuzzy algebraic product is calculated by using Eq. 4 .

When $\lambda$ is 1 in 'fuzzy gamma operation' the combination is identical to 'fuzzy algebraic sum' and when the value of $\lambda$ is 0 the combination is identical to 'fuzzy algebraic product'. Thus, sensible selection of ' $\lambda$ ' may 
provide values as output that will make sure flexible negotiations among decreasing trends in fuzzy algebraic product and increasing tendencies in 'fuzzy algebraic sum' (Lee 2007). For landslide susceptibility study Lee (2007) and Ahmed et al. (2014) have assigned ' $\lambda$ ' values randomly in between 0 to 1 ; as $0.025,0.05,0.1,0.2,0.3$, $0.4,0.5,0.6,0.7,0.8,0.9,0.95$, and 0.975 .

\section{Statistical approaches}

Statistical approaches are the most commonly used methods for landslide susceptibility and hazard zonation (Mengistu et al. 2019; Hamza and Raghuvanshi 2017; Girma et al. 2015; Kanungo et al. 2006). Reviews on various methods developed in past and subsequent evaluation and development of methods has been presented by Reichenbach et al. (2018), Corominas et al. (2014) and Fell et al. (2008). Some of the techniques, which were developed earlier, have been discarded, some methods were modified and new techniques are always being developed (Ayalew and Yamagishi 2005). A thorough literature review made during the present work revealed that the statistical techniques that were used for landslide susceptibility evaluation and zonation by previous researchers can be broadly classified into; Bivariate and Multivariate statistical approaches (Kanungo et al. 2006; Gorsevski et al. 2006a, 2006b; Gorsevski et al. 2000).

Each of these statistical methods showed significant heterogeneity in adopted thematic factors, selected scale, statistical modeling tools used and the methods used for the model performance evaluation and validation. In terms of performance and validation some of these statistical methods may produce better results; however no individual method has proved to be perfect in its performance. In fact integration of these methods into optimal model by utilizing the same thematic factors data and landslide inventory may ideally produce better results than a single model. It needs to be realized that the capability, skill set and experience of an evaluator in applying a particular statistical model is more important than the method by itself (Reichenbach et al. 2018; Corominas et al. 2014). In general, for landslide susceptibility evaluation and zonation approach through statistical modeling as such no established standards and code of practices are available. Thus, it is always a challenge in adopting an appropriate method for landslide susceptibility evaluation. Further, uncertainty always exists on account of its credibility and the results thus produced by the adopted method (Reichenbach et al. 2018; Guzzetti et al. 2006). General limitation of these statistical methods is that they do not propose mechanisms that control slope failure, but rather it assumes that the prediction of future landslide areas can be assessed by measuring the combinations of variables that have led to landslide occurrence in the past (Safaei et al. 2011; Lee et al. 2004; Guzzetti et al. 1999).

Bivariate statistical approach The bivariate statistical approach is based on an inductive logic, which suggests that if a situation holds in all observed cases than the situation holds in all cases. Thus, these techniques are based on a general assumption that "past and the present are the key for future" (Dai and Lee 2001). For landslide studies it is generally assumed that the combination of conditions pertaining to various causative factors may possibly lead to landslide in a given area. Therefore, evaluation of these factors and their relation with the past landslides in the area may form the basis for the prediction of potential areas where landslides may occur in future (Chimidi et al. 2017; Negassa and Kala 2015; Girma et al. 2015; Lan et al. 2004; Dai et al. 2002). In bivariate statistical techniques contribution of individual causative factors in inducing landslide in an area is evaluated separately. Such contribution of various causative factors in inducing landslides is assessed quantitatively through density ratio. The density ratio is derived through overlay analysis where each of the causative factor layers is overlaid over landslide inventory distribution layer. The overlay analysis will thus provide a ratio between landslide that 'did' occur to the landslide that 'did not' occur within each causative factor class (Hamza and Raghuvanshi 2017; Dai and Lee 2001; Lee and Min 2001). Further, combining these density ratios for various factor classes will form the basis for landslide hazard evaluation and zonation in the given area. The commonly used methods for landslide susceptibility and hazard zonation that fall under bivariate statistical approach are; Frequency Analysis (likelihood ratio) method (Lee and Min 2001), Weighted overlay model (Ayele et al. 2014), Weights of Evidence Model (Mohammady et al. 2012), Information Value Model (IV) (Mengistu et al. 2019), Fuzzy logic method (Lee 2007; Chacón et al. 2006; Kanungo et al. 2006; Gorsevski et al. 2003) etc.

\section{(i) Frequency Analysis (likelihood ratio) method}

Among the bivariate statistical approaches Frequency analysis is the most commonly used method (Chimidi et al. 2017; Hamza and Raghuvanshi 2017; Girma et al. 2015; Lee and Min 2001). This method utilizes the correlation between each of the responsible causative factor classes and the spatial distribution of past landslides in the area (Chimidi et al. 2017; Girma et al. 2015; Moung-Jin et al. 2014; Akgun et al. 2012; Pradhan and Lee 2009; Lee 2005). The frequency analysis method is based on the ratio of landslides in a factor class as a percent of landslides to the area of the factor class as a 
percent to the entire area. This frequency ratio is normalized to ' 1 '. Thus, a frequency ratio for a parameter class greater than one shows strong correlation to the occurrence of landslide whereas a frequency ratio less than one indicates lower correlation of the factor class with the landslides (Chimidi et al. 2017; Girma et al. 2015; Lee and Min 2001). The frequency ratio $\left(\mathrm{FR}_{\mathrm{d}}\right)$ can be expressed as (Eq. 7);

$$
F R_{d}=\frac{\% L s}{\% A m}
$$

Where; ' $F R_{d}$ ' is the Frequency ratio for the causative factor class, ' $\% L s$ ' is the percentage of landslides in a causative factor class and ' $\% A m$ ' is the area of the causative factor class as a percentage of the entire map.

Further, the landslide susceptibility index (LSI) for each pixel is the summation of total overlapped pixels and is given by Eq. 8;

$$
L S I=\sum_{d=1}^{n} F R_{d}
$$

If the LSI value is high the landslide hazard is considered to be high. The LSI can also be represented as landslide hazard index (LHI) (Pradhan and Lee 2009).

(ii) Weights of Evidence (WOE) method

Weight of evidence (WOE) method is widely used for the prediction of potential susceptible areas for landslides (Süzen and Doyuran 2004; Van Westen et al. 2003; Van Westen 1993). This method is used to combine the dataset of landslides through a quantitative data-driven approach. With the WOE method prior probability $\left(\right.$ Prior $\left._{\mathrm{P}}\right)$, Conditional probabilities $\left(\operatorname{Cond}_{\mathrm{P}}\right)$ and negative and positive weights of landslide susceptibility can be calculated. For 'Prior ${ }^{p}$ ' the landslide density has to be computed as the total number of pixels within the area covered by the landslides to the total number of pixels in the area under study. 'Prior ${ }_{\mathrm{P}}$ ' can be expressed as Eq. 9;

$$
\operatorname{Prior}_{P}=P\{S\}=\frac{N_{\text {Pix }}(\text { Slide })}{N_{\text {Pix }}(\text { total })}
$$

Where; 'Prior ${ }_{\mathrm{P}}$ ' is the prior probability, $\mathrm{P}\{\mathrm{S}\}$ is the conditional probability of having a landslide ' $\mathrm{S}$ '; $\mathrm{N}_{\mathrm{Pix}}$ (slide) is the total number of pixels within the landslides in the area of study and $\mathrm{NP}_{\mathrm{ix}}$ (total) is the total number of pixels in the area of study.

The Conditional probabilities $\left(\operatorname{Cond}_{\mathrm{P}}\right)$ is the ratio between the total number of pixels of a corresponding factor class within the landslides to the total number of pixels of that factor class within the area of study (Van Western 2002). This can be expressed by Eq. 10;

$$
\text { Cond }_{P}=P\left\{\frac{S}{B}\right\}=\frac{P\{\operatorname{Sn} B\}}{P\{B\}}=\frac{N_{P i x}\{\operatorname{Sn} B\}}{N_{P i x}\{B\}}
$$

Where; 'Cond $\mathrm{p}_{\mathrm{p}}$ ' is the conditional probability of having landslide ' $\mathrm{S}$ ' in a given parameter class ' $\mathrm{B}$ ', ' $\mathrm{N}_{\mathrm{Pix}}\{\mathrm{SnB}\}$ ' is the total number of pixels of a parameter class ' $\mathrm{B}$ ' within the landslides and ' $\mathrm{N}_{\mathrm{Pix}}\{\mathrm{B}\}$ ' is the total number of pixels of that factor class ' $\mathrm{B}$ ' within the total area of study.

Weight of evidence (WOE) method determines the weight for all considered predictive causative factors (B) with respect to absence or presence of the landslides in the area (Mohammady et al. 2012; Bonham-Carter 1994).

$$
\begin{aligned}
& W_{i}^{+}=\operatorname{In}\left(\frac{P\left\{\frac{B_{i}}{S}\right\}}{\left\{\frac{B_{i}}{\bar{S}}\right\}}\right) \\
& W_{i}^{-}=\operatorname{In}\left(\frac{P\left\{\frac{\bar{B}_{i}}{S}\right\}}{\left\{\frac{\bar{B}_{i}}{\bar{S}}\right\}}\right)
\end{aligned}
$$

Where, 'In' is the natural log, ' $P$ ' is the probability, 'Bi' is the presence of potential landslide predictive causative factor, ' $\bar{B}_{i}$ ' is the absence of the potential landslide predictive causative factor, ' $\mathrm{S}$ ' is the presence of landslide and ' $\bar{S}$ ' is the absence of landslide, ' $W_{i}^{+}$' represents a positive weight which implies that predictable factor is present in landslide, ' $W_{i}^{-}$' represents a negative weight which suggests absence of predictable factor in the landslide.

\section{(iii) Information Value (IV) method}

In information value (IV) method the weighted class value is computed through density of landslides with respect to each causative factor. For spatial landslide prediction and zonation, information value method has been utilized by many researchers such as; Mengistu et al. (2019), Balasubramani and Kumaraswamy (2013), Yalcin (2008), Lin and Tung (2003), Zêzere et al. (2004), Jade and Sarkar (1993), Yin and Yan (1988) etc.

The information values of various causative factors can be used to determine the possible areas of landslide occurrence which may facilitate in landslide hazard zonation. Based on the presence or absence of the causative 
factor classes within the past landslides the Information values can be determined. In order to calculate the weights for respective classes the landslide map can be combined with the causative factor maps. Thus, landslide density for causative factor sub-classes can be determined by overlaying the causative factors map on the inventoried landslide map (Mengistu et al. 2019). According to Yin and Yan (1988), if the information value is positive the causative factor class represents strong relationship with the landslides in the area. According to Van Westen et al. (1997) the weighted value of a causative factor class can be represented as the natural logarithm of density of landslide in a factor class, divided by landslide density in the total map area. The Information value method is also named as landslide index $\left(W_{i}\right)$ method. The information value can be computed by utilizing eqs. 13 to 16 (Yin and Yan 1988);

$$
\text { Conditional probablity }(C P)=\frac{N_{P i x}\{S B i\}}{N_{P i x}\{B i\}}
$$

$$
\text { Priorprobablity }(P P)=\frac{N_{P i x}\{T S\}}{N_{P i x}\{A\}}
$$

$$
\text { Weight of factor class }(W B i)=\frac{C P}{P P}
$$

$$
\text { Information value }(I V)=\log (W B i)
$$

Where; ' $\mathrm{N}_{\mathrm{Pix}}\{\mathrm{SBi}\}$ ' is the number of landslide pixels within the factor class, $\mathrm{N}_{\mathrm{Pix}}\{\mathrm{Bi}\}$ is the number of pixels of a factor class, ' $\mathrm{N}_{\text {Pix }}\{\mathrm{TS}\}$ ' is the total sum of pixels of landslide of the whole study area and $\mathrm{N}_{\text {Pix }}\{\mathrm{A}\}$ is the total pixels of the whole study area.

Once the Information values are obtained, the respective IVs can be assigned to each factor class and the weighted causative factor maps can be prepared. These causative factor maps can further be processed in GIS environment and landslide susceptibility index (LSI) can be computed (Eq. 17) for each pixel with the help of raster calculated. Thus, this LSI will form the basis to produce the landslide hazard zonation map (Mengistu et al. 2019).

$$
L S I=\sum I V B
$$

Where; LSI is the landslide susceptibility index and " $\Sigma I V B^{\prime}$ is the sum total of information values for all causative factors.
Multivariate statistical approach The landslide susceptibility and hazard zonation through multivariate statistical approach is based on the relationship of relative contribution of each of the causative factor to the total landslide susceptibility in the area (Nandi and Shakoor 2009; Kanungo et al. 2009; Ayalew and Yamagishi 2005; Süzen and Doyuran 2004; Dai et al. 2001). In multivariate methods for landslide susceptibility analysis, percentage of landslides for each pixel is determined and data layer on landslide presence or absence is developed through statistical analysis. The commonly used multivariate statistical methods for landslide susceptibility and hazard zonation are; Logistic regression model, multiple regression models and Discriminant analysis (Kanungo et al. 2006; Guzzetti et al. 1999; Chung and Fabbri 1995; Van Westen 1993; van Westen 1994; Yin and Yan 1988).

\section{(i) Logistic regression method}

Among various multivariate statistical methods Logistic regression is the most popular method used for the spatial prediction of landslide susceptibility and hazard zonation (Wu et al. 2015; Schicker and Moon 2012; Gorsevski et al. 2000). The logistic regression method is capable of predicting a binary response variable such as presence or absence of landslides through categorical and continuously scaled predictors (Steger et al. 2016; Goetz et al. 2015; Felicísimo et al. 2012; Pradhan and Lee 2009; Van Den Eeckhaut et al. 2006; Atkinson and Massari 1998). This method is applied to predict the probability of occurrence of landslides following the logistic regression statistical analysis. The relationship between the occurrence of landslides in the area and its dependency on several variables (causative factors) can be defined through Eq. 18 (Ayalew and Yamagishi 2005; Menard 1995).

$$
P=\frac{1}{1+e^{-z}}
$$

Where; ' $\mathrm{P}$ ' is the estimated probability of a landslide occurrence which varies from 0 to 1 on a'S shaped' curve. The term ' $z$ ' represents a linear combination. The logistic regression utilizes fitting of an equation (19) to the data set;

$$
z=b_{0}+b_{1} x_{1}+b_{2} x_{2}+b_{3} x_{3}+\ldots \ldots+b_{n} x_{n}
$$

Where; ' $b_{0}$ ' represents the intercept of the model, the $b_{i}(i=0,1,2, \ldots, n)$ are the slope coefficient of the logistic regression model and the $x_{i}(i=0,1,2,3 \ldots \ldots \ldots, n)$ represents the independent variable. 
Logistic regression is applicable for the situations where either the data is continuous or discrete or combination of both. This is the main advantage of logistic regression method. However, the results of logistic regression cannot identify the influence of different classes on landslide occurrence. To apply logistic regression the dependent variable should be binary, for example yes or no, zero or one, absence or presence etc. (Lee 2015; Chen and Wang 2007).

\section{(ii) Discriminant method}

Discriminant method is a commonly used method for landslide susceptibility and hazard zonation. It is a multivariate statistical model in which the dependent variable is considered to be categorical rather than continuous (Gorsevski et al. 2000). The discriminant analysis facilitates to know the maximum difference for each landslide causative factors (independent variable) among non-landslide group and the landslide group. Thus, it forms the basis to calculate the weights for these causative factors (Pardeshi et al. 2013; Lee et al. 2008). The slope units can be classified to account for landslide free and the landslide affected classes. Further, by determining the Standardized Discriminant Function Coefficient (SDFC) relative significance of each variable can be expressed in terms of discriminant function as a predictor of potential slope instability. Variable that shows high coefficient are strongly correlated to absence or presence of the landslide (Pardeshi et al. 2013; Guzzetti et al. 2005b).

\section{Artificial intelligence (Al) methods}

Artificial intelligence (AI) method uses some of the statistical concepts. However, these methods are based on assumptions, predetermined algorithms and output. AI methods are suitable when a direct mathematical relationship cannot be established between cause and effect (Chowdhury and Sadek 2012). There are number of AI methods or machine learning methods (Kavzoglu et al. 2018) that can be used for the landslide studies. These can be categorized as; artificial neural network (ANN), fuzzy based, hybrid, kernel based and tree based (decision tree) methods. Further, there are number of sub methods under each category, for instant, ANN-adaptive neuro-fuzzy inference system, back-propagation neural network etc.; fuzzy based- fuzzy clustering; hybrid-SVMparticle swarm optimization; kernel based-kernel logistic regression, SVM (support machine vector); tree basedbagging, decision trees, random forest etc. (Đurić et al. 2019; Kavzoglu et al. 2018; Goetz et al. 2015) etc. AI methods are effective regardless of data dimension (i.e., the number of conditioning factors) and data type (applicable to deal with discrete and continuous data)
(Đurić et al. 2019; Kavzoglu et al. 2018). Furthermore, they can reveal good generalization performance on many real life issues, they have few parameters to adjust and provide the architecture of learning machines without experimentation (Pawley et al. 2017). Hence, they are more suitable for the analysis of high dimensional data and complex systems.

Artificial neural network (ANN) method ANN method facilitates to obtain, represent and perform mapping of landside susceptibility and hazard from one multivariate space of information into another by providing a set of data or information relating to representative mapping (Pradhan and Lee 2010; Nefeslioglu et al., 2008; Garrett 1994). The landslide is a complex process which is resulted due to combination of various causative and triggering factors. Also, the relationships between the landslides and the causative and triggering factors are considered to be non-linear in nature (Ercanoglu 2005). Therefore, in order to address such non-linear complex relationships between the factors and the landslides ANN method is used which includes back propagation learning algorithm and is capable of developing rules for weight assignment for the respective factors (Kanungo et al. 2006; Yesilnacar and Topal 2005; Gómez and Kavzoglu 2005; Lee et al. 2004; Zhou et al. 2002; Haykin 1999; Ripley 1996).

In ANN, back propagation is used to determine a gradient (Kanungo et al. 2006) which is required to calculate the weights that are used in the network. For landslide susceptibility and hazard zonation back propagation is used as shorthand to the backward propagation of the errors. For this, at the output an error is determined which is distributed backward all along the layers of the network (Pradhan and Lee 2010; Paola and Schowengerdt 1995). The ANN facilitates the database management with qualitative or quantitative information having rules (if/ then) that can infer results. The entry nodes can have quantitative, qualitative, reclassified or direct data. For landslide susceptibility study, landslide densities of different types or determinant causative factor data can be assigned to the entry nodes. The data is processed in the hidden layer nodes by following rules for weighting that depends on the considered importance (Chacón et al. 2006; Zell et al. 1993; Lipmann 1987). Further, the ANN method can manage imperfect or incomplete data and it also allows analyzing nonlinear complex variable relationships between the causative factors and the landslides (Chacón et al. 2006; Lee et al. 2003). The major limitations with ANN method are in its computing time, required for data format conversion to GIS environment and the application complexity owing to the process in the hidden layers (Chacón et al. 2006). The ANN method is only applicable for landslides 
which are shallow and it has limitation for deep seated landslides (Basma and Kallas 2004; Neaupane and Achet 2004).

Support vector machines (SVM) This method is used to solve complex classification and regression problems (Tien Bui et al. 2015; Kavzoglu et al. 2013; Ballabio and Sterlacchini 2012; Kavzoglu and Colkesen 2009; Brenning 2005). SVMs are originally developed as a binary classifier aiming to find a linear hyperplane that separates two classes optimally (Vapnik 1999). For binary classification problems, SVMs attempt to find a separating hyperplane in the feature space such that the distance between the positive and negative samples is maximized for the linearly separable case (Kavzoglu et al. 2013). The hyperplane providing maximum margin between two classes is called optimum hyperplane and the points that constrain the width of the margin are called support vectors. In many classification and regression problems, it is difficult to separate data linearly. In such cases, the technique can be extended to allow for nonlinear decision surfaces (Cortes and Vapnik 1995).The main idea behind SVM is to find the boundary line that separates the two classes, but in such a way that the boundary line creates a maximum separation between the classes (Han et al. 2019; Kavzoglu et al. 2018; He et al., 2012).

\section{Probabilistic approach}

In order to evaluate landslide susceptibility and hazard zonation the degree of relationship between the past landslide distribution and the causative factors is converted to a value which is based on a probability distribution function. Probabilistic approach helps in prediction of spatial and temporal landslide distribution probability in the given area (Lari et al. 2014; Guzzetti et al. 2005b). The approach utilizes the comparison of spatial landslide distribution with the considered causative factors (explanatory variables) in a framework of probabilistic theory (Lari et al. 2014; Kanungo et al. 2009; Straub and Schubert 2008). The probabilistic approach though considered quantitative however it has certain degree of subjectivity in assignment of weights to various causative factors (Kanungo et al. 2006). Thus, probabilistic approach may be considered as semiquantitative.

\section{Deterministic approach}

Deterministic approach accounts for landslide hazard evaluation following mechanical laws. These methods includes empirical methods (Raghuvanshi, 2019; Liu and Chen 2007; Hack 1998; Anbalagan 1992; Romana 1985; Selby 1980), kinematic methods (Raghuvanshi, 2019; ZainAlabideen and Helal 2016; Karaman et al. 2013; Kulatilake et al. 2011; Goodman 1989), static infinite slope modeling (Pack et al. 1998; Dietrich et al. 1995), dynamic infinite slope modeling (Simoni et al. 2008; Baum et al. 2002), 2-D (Sharma et al. 1995; Hoek and Bray 1981) and 3-D limit equilibrium and numerical modeling (Raghuvanshi, 2019; Tang et al. 2016; Karaman et al. 2013; GEO-SLOPE 2011; Gitirana Jr. et al. 2008; Stead et al. 2006; Hungr and Rawlings 1995). The main factors that are considered for deterministic techniques are; slope geometry, discontinuity characteristics and its relation to the slope, groundwater condition and surface drainage (Raghuvanshi, 2019; Wang and Niu 2009; Ayalew et al. 2004; Turrini and Visintainer 1998; Anbalagan 1992), rainfall, seismicity and manmade activities (Girma et al. 2015; Raghuvanshi et al. 2014a, 2014b; Wang and Niu 2009; Dahal et al. 2006; Gorsevski et al. 2006b; Malamud et al. 2004; Bommer and Rodri'guez 2002; Keefer 2000) etc. It is believed that all these factors in combination will be responsible for the landsides or relative instability of slopes (Raghuvanshi, 2019). The deterministic techniques do not require long term data. Also, landslide inventory data is not required (Kuriakose 2010). These techniques primarily rely on the physical laws that are responsible in defining the stability of slope (Guzzetti et al. 2000). Since the deterministic techniques require detailed data on geotechnical parameters therefore collecting such detailed data over large areas make these techniques limited to small areas, effectively limited to individual slopes (Raghuvanshi et al. 2014a, 2014b; Fall et al. 2006; Kanungo et al. 2009; Aleotti and Chowdhury 1999).

\section{Validation methods}

All statistical methods, machine learning or artificial intelligence and some of the semi-quantitative approaches are tested by field observations and statistical tests. Sample field observation may be applicable for every type of landslide studies except for small area or single landslide studies. However, statistical validations are used for statistical, AI and semi-quantitative approaches such as AHP, fuzzy logic etc. Receiver operator characteristic (ROC) is used for statistical, AI and semiquantitative approaches. For multivariate statistical approaches there are different validation methods starting from data reliability to model accuracy in addition to ROC. In order to check the performance of the prediction ability of the above mentioned methods the most popular technique is receiver operator characteristic (ROC) curve. The ROC curve represents a plot of the probability with true positive identified landslides against the probability of false identified landslides, as the cutoff probability varies (Gorsevski et al. 2006a). With the selection of decision parameter that adjust the tradeoff between the proportion of correctly identified pixels and the incorrectly identified pixels, the ROC performance 
curve can be varied systematically (Kavzoglu et al. 2014; Swets 1988). Other validation methods that can be used are landslide density analysis, landslide percentage comparison, relative landslide density index; relative error etc.

\section{Advantage and limitation of each method}

The different methods used for landslide susceptibility analysis has their own advantage and disadvantage owing to its application, data procurement and scales at which these can be applied (Raghuvanshi et al. 2014a, 2014b; Fall et al. 2006; Kanungo et al. 2006; Casagli et al. 2004; Guzzetti et al. 1999; Leroi 1997).

Geomorphological methods can be applied in relatively short period of time at low cost. These methods can be applied in relatively large areas (small scale map) and can cover inaccessible area through various multitemporal satellite image interpretations (Chelli et al. 2015; Delmonaco et al. 2013; Guzzetti et al. 1999). Since these methods are applied at small scale therefore geomorphological details considered in these methods are limited (Guzzetti et al. 2005a, 2005b; Ibsen and Brunsden 1996). Thus, the reliability and application of results is limited for specific purpose. Similarly, the limitations of landslide inventories refer to their subjectivity and to the difficulty of assessing their reliability. The reliability of archive inventories depends largely on the quality and abundance of information sources (Raghuvanshi et al. 2014a; Guzzetti et al. 2005a, 2005b; Cruden and Varnes 1996; Ibsen and Brunsden 1996;).

Further, the advantage in heuristic evaluation technique is in its simplicity. The weight assigned by the expert to various causative factors do not need historical data base and are simply based on the judgment of relative contribution of each parameter class. These techniques are popular because of their simplicity in application. These techniques are based on data, primarily acquired from the field and are well supported by the judgment and experience of an evaluator (Raghuvanshi et al. 2014a, 2014b). However, the major disadvantage of these techniques is in its subjectivity in assigning weight and ratings to the parameter classes (Raghuvanshi et al. 2014a; Delmonaco et al. 2013; Guzzetti et al. 1999). Thus, the landslide susceptibility evaluated by heuristic technique may vary considerably if evaluated by different experts.

The statistical approaches are primarily based on statistical relationship between past landslides and various causative factors. In these techniques the weights for various causative factors are determined statistically (Dai and Lee 2001). These techniques are based on the analysis of functional relations between instability factors (thematic variables) and the past and present distribution of slope failures (landslide inventory) (Negassa and
Kala 2015; Guzzetti et al. 2000). The advantage of statistical techniques is that these techniques can be applied over a large area and the ratings for various factor classes can be deduced statistically from the past landslide data. However, the limitation of these methods is in collection of past landslide inventory data over large areas. Since the general rules for landslide susceptibility are formulated from the past landslide data therefore well distributed past landslides in the study area will ensure good quality results. Thus, the type, extent and distribution of past landslide data in the study area is a necessary input for all statistical techniques (Negassa and Kala 2015).

Additionally, the statistical models require large efforts to collect and validate the necessary input data, which are often not readily available. Besides, for better results, interaction is required between geomorphologists and the statisticians to process the landslide and geoenvironmental data to avoid unrealistic results. Further, statistical models are influenced (negatively) by the extent of the study area, making it difficult to compare susceptibility classes from different locations. Also, often susceptibility maps prepared by statistical methods are difficult to understand by a non-specialists, including planners and policymakers (Reichenbach et al. 2018; Raghuvanshi et al. 2014a, 2014b; Fall et al. 2006; Van Westen et al. 2003; Van Westen et al. 1997).

Artificial intelligence (AI) applications are utilized to simulate human intelligence for either solving a problem or making a decision. AI provides the advantages of permanency, reliability, and cost-effectiveness while also addressing uncertainty and speed in either solving a problem or reaching a decision (Chowdhury and Sadek 2012).

The main advantage of using ANN methods is that there is no need for statistical variables in the process. The ANN methods allow the target classes to be defined in relation to their distribution in each source data set, facilitating the integration of data emerging from remote sensing, GIS, etc. Further, the time involved is shorter than required for most statistical techniques and calculation pixel by pixel is possible. The method allows incomplete or imperfect data to be managed as well as the analysis of interactions between non-linear or complex variables (Chacón et al. 2006; Lee et al. 2003). According to Chacón et al. (2006) ANN has limitations that are complexity for application due to the internal process within the hidden layers and the amount of computing time needed for changes in data format to be used in GIS. Also it has limited application in deep landslides, rather it can mainly be used for shallow landslide (Basma and Kallas 2004; Neaupane and Achet 2004).

Geotechnical modeling or deterministic approach relies upon the understanding of the physical laws that 
control the slope instability (Guzzetti et al. 2000). Geotechnical modeling are useful for quantitative investigation for landslides, however these techniques are useful only in areas of limited extent due to difficulty of collecting geotechnical data with appropriate resolution over larger regions (Negassa and Kala 2015; Kanungo et al. 2009; Aleotti and Chowdhury 1999).

\section{Selection criteria}

As discussed, there are several techniques available for evaluation of landslide susceptibility and hazard zonation. The choice of selection of appropriate technique for landslide study will depend on the criteria such as; investigation purpose, the extent of the area to be covered, the types of mapping units, the scale of map to be produced, type of data to be used, type of landslides, availability of resources, capability and skill set of evaluator, accessibility of the study area etc. (Guzzetti et al. 2000, 2012; Van Westen et al. 2005).

The landslide studies may be carried out for various purposes these may be primarily for construction sites, regional land-use planning, and evaluation of susceptibility of an area, for hazard zonation and mitigation measures. For each of these purposes specific type of technique has to be followed. Landslide studies for new construction sites requires techniques that may provide quantitative results of slope stability that may directly be utilized for design purpose. These studies are site specific and needs to be carried out at large scale (Raghuvanshi et al. 2014a, 2014b; Fall et al. 2006). The most appropriate techniques which may provide required results are deterministic techniques (Chimidi et al. 2017; Negassa and Kala 2015; Kanungo et al. 2006). Further, if the purpose is for regional planning, depending on the area coverage, heuristic or statistical techniques may be followed. The heuristic techniques generally require considerable field data (Ermias et al. 2017; Raghuvanshi et al. 2014a, 2014b) therefore these techniques may be conveniently applied at local scale. However, statistical techniques may be conveniently applied at medium scale. In some cases, depending on the purpose, integration of techniques may also be followed to get the desired results.

The scale of mapping will depend on the extent of the area to be covered, the purpose for which landslide study has to be carried out and the availability of data and resources (Huabin et al. 2005; Aleotti and Chowdhury 1999). The different scales proposed for landslide studies has been classified as; detail scale $(>1: 5000)$, large scale $(<1: 5000-1: 10,000)$, Medium scale $(1: 25,000-1: 50,000)$ and Regional scale $(<1: 250,000)$ (Huabin et al. 2005). Similarly, IAEG, Commission on Landslides (1990) and CEOS (2001) have classified landslide mapping scales as; Large scale (1:5000-1:15,000), Medium scale (1:25,000$1: 100,000)$, Regional scale $(1: 100,000-1: 500,000)$ and
National scale $(<1: 500,000)$. The detail scale or large scale are applicable for construction sites where deterministic techniques are applied for slope stability evaluation and where only single element at risk is considered (Corominas et al. 2014). The medium scale is applicable for land-use planning where evaluation of susceptibility of the area and hazard zonation is required. The landslide studies at medium scale are required at the preliminary stage of regional developmental plans or for the evaluation of the possible instability problems related to the development of large engineering projects such as; dam and reservoir projects.

The maps prepared at medium scale delineate the areas that are susceptible for landslides and may be a constraint for the development of engineering projects. However, they do not provide required data for design purpose (Soeters and Van Westen 1996). Further, landslide studies at national mapping scale are carried out covering very large areas. Studies at such scale are basically carried out to facilitate national policy makers. These maps will provide low level of details as the investigation is carried out by following general rules (Corominas et al. 2014; Soeters and Van Westen 1996). Table 1 shows the application of various landslide susceptibility and hazard zonation techniques at different scales, as sourced and modified from the works of Soeters and van Westen (1996) and Aleotti and Chowdhury 1999).

Other important criteria related to selection of appropriate technique for landslide studies is related to the type of data to be used. The method by which the required primary data on causative factors and landslide inventory will be collected and the secondary data that is available often forms the basis to adopt the appropriate technique for landslide studies. If systematic multi-stage historical landslide registered data in good quality and quantity is available statistical approaches may be applied effectively. However, such systematic data, in most of the cases, is not maintained by the concerned authorities (Girma et al. 2015; Negassa and Kala 2015). Thus, the landslide inventory data is produced through remote sensing and field based investigations. However, the manifestations for past landslides may not always be visible due to vegetation cover or due to displaced soils or due to erosional processes. Thus, the landslide inventory data generated through remote sensing or through field investigation may not be complete and the landslide susceptibility evaluated may not always produce actual results. Also, if systematic multi-temporal data on past landslides and other governing factors is amply available both statistical and probabilistic approaches can be applied effectively for landslide studies. The deterministic techniques are scale dependent and may require good quality of geological and geotechnical data (Raghuvanshi et al. 2014a). Therefore, deterministic techniques needs 
Table 1 Application of various landslide susceptibility and hazard zonation techniques at different scales (Modfied from Soeters and Van Westen 1996; Aleotti and Chowdhury 1999)

\begin{tabular}{|c|c|c|c|c|c|}
\hline \multirow[t]{3}{*}{ Mapping Scale } & \multicolumn{5}{|c|}{ Landslide susceptibility and hazard zonation techniques } \\
\hline & \multicolumn{2}{|l|}{ Qualitative } & \multicolumn{3}{|l|}{ Quantitative } \\
\hline & Inventor & Heuristic analysis & Statistical analysis & Process based analysis & Neural network analysis \\
\hline$>1: 10,000$ & Applicable & Applicable & Not applicable & Applicable & Applicable \\
\hline $1: 25,000-1: 50,000$ & Applicable & Applicable & Applicable & Not applicable & Not applicable \\
\hline$<1: 100,000$ & Applicable & Not applicable & Not applicable & Not applicable & Not applicable \\
\hline
\end{tabular}

to be adopted only when the study area is relatively small and the possible resource to generate good quality geological and geotechnical data is available. Further, most of the heuristic approaches do not require detailed landslide inventory data however; they may require considerable field data (Girma et al. 2015; Raghuvanshi et al. 2014a) on various parameters, particularly on geological factors. Thus, the heuristic techniques may only be considered when the study area is relative small, area is well accessible for field investigation and sufficient time and resource is available.

\section{Discussion}

Landslide is a complex process that is resulted due to combination of several inherent causative and external triggering factors (Raghuvanshi et al. 2014a; Anbalagan 1992). For landslide susceptibility evaluation it is important to know these factors and to asses there possible influence in inducing instability to the slopes. A basic assumption which is followed in most of the techniques in landslide studies, particularly for quantitative techniques is that; the combination of causative factors that has lead to the past landslides in an area if reoccur in other areas, again landslides can be expected. Therefore, it is important to evaluate causative factors and assess their possible relationship with the past landslides in the area; this will form the basis for the prediction of the potential areas where landslides may occur in future (Chimidi et al. 2017; Girma et al. 2015; Negassa and Kala 2015).

The qualitative approaches can effectively be applied at small or large scale and are used to delineate the potential landslide areas. The landslide inventory approach, which is direct mapping method, are used to show the landslide distribution in the area and they also provide data for landslide density analysis (Reichenbach et al. 2018; Guzzetti et al. 1999; Soeters and Van Westen 1996). The landslide inventory mapping is the most straight-forward and are basic input for most of the quantitative approaches (Chimidi et al. 2017; Negassa and Kala 2015; Lan et al. 2004; Dai et al. 2002). Landslide inventory approaches are focused to analyze distribution of landslides, to classify the landslides, to evaluate the temporal change in pattern of landslides and to determine density of landslides in various terrain units
(Guzzetti et al. 2012). Further, the indirect method includes geomorphological mapping and techniques that are based on qualitative map combinations. These techniques include assessment of parameters that have significant influence on landslide process. These techniques involve combination of various causative factor maps. For this, based on the expert opinion weight and ratings are assigned to causative factors and the factor classes (Reichenbach et al. 2018; Raghuvanshi et al. 2014a; Ayalew and Yamagishi 2005; Anbalagan 1992). In general, the indirect approaches; heuristic approaches are subjective in nature and greatly depend on the expert opinion and evaluation (Guzzetti et al. 1999; Aleotti and Chowdhury 1999). However, they are simple in application and can utilize more actual field observed data well supported by the experience of an evaluator (Raghuvanshi et al. 2014a).

Most of the statistical techniques can effectively be applied at medium scale (Girma et al. 2015; Fell et al. 2008; Lee and Min 2001). Also, statistical techniques can be applied at small scale however the results thus produced are less reliable. Since, statistical techniques are based on historical landslide inventory data therefore collection of such data over very large areas is practically not feasible. Thus, because of this limitation at small scale the statistical techniques may not provide reliable results.

Artificial intelligence (AI) methods have an advantage of permanency, reliability, and cost-effectiveness and they also address uncertainty and rapid means of solving a problem for quick decision (Chowdhury and Sadek 2012).Further, the ANN methods allow the target classes to be defined in relation to their distribution in each source data set, facilitating the integration of data produced from various sources. The process requires less time as compared to other statistical techniques. The method allows analysis of interactions between nonlinear or complex variables (Chacón et al. 2006; Lee et al. 2003). ANN has limited application in deep landslides and can conveniently be used for shallow landslide evaluation (Basma and Kallas 2004; Neaupane and Achet 2004).

The deterministic techniques are most suitable when applied at large scale, as these techniques require 
considerable field data on geological and geotechnical parameters. Ideally, they are most suitable for construction sites and these techniques may produce results that can directly be used for the design purpose (Chimidi et al. 2017; Negassa and Kala 2015; Kanungo et al. 2006). Moreover, the quantitative techniques are reliable as these are objective in nature and the predictions for landslide susceptibility or slope instability is based on the actual realistic data and interpretations. The quantitative techniques overcome the subjectivity owing to expert evaluations and are capable of producing repeatable results (Safaei et al. 2011; Carrara et al. 1991; Carrara et al. 1992; Carrara et al. 1995).

Often it is difficult to make a choice on the selection of an appropriate approach for landslide susceptibility evaluation and hazard zonation mapping. It is reasonable to consider factors that may guide to adopt an appropriate approach. These factors are related to investigation purpose, the extent of the area to be covered, the types of mapping units, the scale of map to be produced, type of data to be used, type of landslides, availability of resources, capability and skill set of an evaluator, accessibility of the study area etc. (Guzzetti et al. 2012; Guzzetti et al. 2000; Van Westen et al. 2005).

The purpose for which the landslide studies needs to be carried out is the most important factor in deciding about the technique. For regional planning purpose statistical or heuristic techniques are most appropriate approaches. The statistical techniques for this purpose may conveniently be applied at medium scale whereas the heuristic techniques may be applied in relatively small area at both medium and large scales. At regional scales heuristic techniques are not practically feasible as these techniques generally requires considerable field data on various causative factors (Ermias et al. 2017; Raghuvanshi et al. 2014a). Therefore, heuristic techniques may be conveniently applied at a local scale. The most appropriate techniques that may be applied at new construction site are the deterministic techniques. These techniques can be applied at large scales, most effectively applied for individual slopes and are capable of providing quantitative results that can directly be applied in engineering design (Chimidi et al. 2017; Raghuvanshi et al. 2014a; Fall et al. 2006; Kanungo et al. 2006). Landslide and related slope stability studies may be required for new project sites that may include road construction sites, canal alignments, building sites on slopes or adjoining to slopes and valley slopes along the dam reservoirs. For all such construction sites the landslide studies needs to be carried out by deterministic or probabilistic approaches, even if the study area is large. For such construction sites the required results must be of quantitative nature that can directly be utilized for the design purpose. The data generated through heuristic or statistical techniques may not be useful for the construction sites as these techniques are only capable of delineating potential hazard zone of landslide susceptibility and the results thus produced cannot be utilized for design purpose. Moreover, for the preliminary study for the road design or for the town planning, inventory or statistical approaches may be adopted to identify the potential landslide and related unstable areas. However, at detailed investigation stage deterministic or probabilistic approaches can be followed.

For landslide studies selection of appropriate mapping units is also important. Different type of mapping units such as; grid cell (pixels), slope unit, terrain units, unique condition units, geo-hydrological units, topographical units and political or administrative units may be adopted (Lee 2015; Guzzetti et al. 1999). For statistical and physical based approaches, grid cell or pixels mapping units in the raster data sets are most appropriate (Reichenbach et al. 2018; Lee 2015; Guzzetti et al. 2006). Similarly, unique condition units are commonly used in probabilistic approaches in both raster and vector data sets (Guzzetti et al. 1999; Carrara et al. 1995; Chung and Fabbri 1995). The primary advantage of adopting unique condition units is in their simplicity by which they can be obtained in GIS environment and in fact relatively they reduces some of the conceptual and operational problems of the grid cells (Reichenbach et al. 2018; Lee 2015) .

Further, the basis to adopt appropriate technique for landslide studies is also guided by the method by which the required data on causative factors will be collected. The collection of required data on causative factors and landslide inventory for various techniques may differ considerably. For statistical approaches systematic multistage historical landslide registered data in good quality and quantity is mandatory, as this data will form the basis for the prediction of potential landslides in the given area. Further, landslide inventory data is often not well maintained by the concerned authorities. Therefore, as a general practice the landslide inventory data is produced through remote sensing and field based investigations. This consumes considerable time and resources. Therefore, availability of data on various causative factors and systematic landslide inventory data will not only save the time but it will also ensure good quality results. The other aspect related to availability of data is related to the area coverage. If secondary data on causative factors and the landslide inventory is available in good quality and quantity, relatively large area can be covered for the landslide study. In contrast non availability of required secondary data for statistical approach will force to restrict the landslide study to limited coverage area. Similarly, the deterministic techniques are scale dependent and may require good quality of geological 
and geotechnical data (Raghuvanshi et al. 2014a). These techniques can only be adopted when the study area is relatively small and the required resource and time to generate good quality of geological and geotechnical data is available.

For relatively small areas, qualitative approaches particularly heuristic approaches are effective for the delineation of the potential landslide susceptible areas. Most of the data collections in the direct method or geomorphological analysis are through remote sensing sources, supplemented and verified from the field observations. In general, medium scale mapping is used to investigate landslide susceptibility and hazard zonation by using statistical, heuristic and probabilistic approaches. Large scale mapping is used to investigate specific area particularly for construction purpose or for landslide hazard mitigation.

\section{Conclusion}

For proper landslide mitigation and management, susceptibility evaluation and hazard zonation is very important. Landslides are influenced by several inherent causative and external triggering factors that vary significantly from place to place. Proper evaluation of these factors is essential for landslide studies. Each of these factors may influence landslide process and in combination they result into landslide activity. Further, various approaches that are used for landslide evaluation studies can broadly be divided into qualitative and quantitative approaches. Qualitative approaches include geomorphological analysis (inventory approach) and heuristic techniques (knowledge based approach) whereas quantitative approach includes statistical and deterministic techniques. The qualitative approaches can effectively be applied at small or large scale and are used to delineate the potential landslide areas. Statistical approaches are the most commonly used methods for landslide susceptibility and hazard zonation. The statistical techniques can be classified into; Bivariate and Multivariate statistical approaches. In bivariate statistical techniques contribution of individual causative factors in inducing landslide in an area is evaluated separately. Such contribution of various causative factors in inducing landslides is assessed quantitatively through density ratio. Combining these density ratios for various factor classes will form the basis for landslide hazard evaluation and zonation in the given area. The commonly used methods under bivariate statistical approach are; Frequency Analysis (likelihood ratio) method, Weighted overlay model, Weights of Evidence Model, Information Value Model (IV) and Fuzzy logic methods. The multivariate statistical approach is based on the relationship of relative contribution of each of the causative factor to the total landslide susceptibility in the area. In multivariate methods, percentage of landslides for each pixel is determined and data layer on landslide presence or absence is developed through statistical analysis. The commonly used multivariate statistical methods are; Logistic regression model, multiple regression models, Discriminant analysis, conditional analysis and Artificial Neural Networks (ANN).

The quantitative techniques are reliable as these are objective in nature and the predictions for landslide susceptibility or slope instability is based on the actual realistic data and interpretations. The quantitative techniques overcome the subjectivity, owing to the expert evaluations and are capable of producing repeatable results. Further, for the selection of appropriate technique for landslide hazard evaluation and zonation the factors that may be considered to adopt an appropriate approach are; investigation purpose, the extent of the area to be covered, the types of mapping units, the scale of map to be produced, type of data to be used, type of landslides, availability of resources, capability and skill set of an evaluator and accessibility of the study area. Finally, landslide is a complex natural geo-hazard and it requires good understanding on the governing factors. It is necessary to adopt appropriate technique for the landslide evaluation and zonation, for which above mentioned selection criteria needs to be followed.

\section{Acknowledgements \\ The authors are thankful to Department of Applied Geology, Addis Ababa Science and Technology and Arba Minch Universities, Ethiopia for extending all kinds of support during compilation of the present review work.}

\section{Authors' contributions}

The first author Mr. Leulalem Shano compiled this paper from different sources; technical articles, books and conference papers. Dr. Tarun K. Raghuvanshi thoroughly reviewed technical contents, provided required inputs and improved general organization of this manuscript. The third author Dr. Matebie Meten provided necessary technical input and enhanced the overall quality of the manuscript. The author(s) read and approved the final manuscript.

\section{Authors' information}

Not applicable.

\section{Funding}

No funding was used for this manuscript preparation.

Availability of data and materials

All materials used for the article compilation are properly cited.

\section{Competing interests}

The authors have no competing interest.

\section{Author details}

'Department of Geology, College of Natural Sciences, Arba Minch University, Arba Minch, Ethiopia. ${ }^{2}$ School of Earth Sciences, College of Natural Sciences, Addis Ababa University, PO Box 1176, Addis Ababa, Ethiopia. ${ }^{3}$ Department of Geology, College of Applied Sciences, Addis Ababa Science and Technology University, Addis Ababa, Ethiopia. 
Received: 20 November 2019 Accepted: 8 April 2020 Published online: 20 May 2020

\section{References}

Abija FA, Nwosu Jl, Ifedotun Al, Osadebe CC (2020) Landslide susceptibility assessment of Calabar, Nigeria using geotechnical, remote sensing and multi-criteria decision analysis: implications for urban planning and development. SDRP J Earth Sci Environ Stud 4(6):774-88

AGS (Australian Geomechanics Society) (2000) Landslide risk management concepts and guidelines. Australian Ge-omechanics Society, Sub-Committee on Landslide Risk Management, Australian Geomechanics, vol 35, pp 49-92

Ahmed B (2015) Landslide susceptibility mapping using multi-criteria evaluation techniques in Chittagong metropolitan area, Bangladesh. Landslides 12(6): 1077-95

Ahmed MF, Rogers JD, Ismail EH (2014) A regional level preliminary landslide susceptibility study of the upper Indus river basin. Eur J Remote Sensing 47(1):343-73

Akgun A, Sezer EA, Nefeslioglu HA, Gokceoglu C, Pradhan B (2012) An easy-touse MATLAB program (MamLand) for the assessment of landslide susceptibility using a Mamdani fuzzy algorithm. Comput Geosci 38(1):23-34

Aleotti P, Chowdhury R (1999) Landslide hazard assessment: summary review and new perspectives. Bull Eng Geol Environ 58(1):21-44

Anbalagan R (1992) Landslide hazard evaluation and zonation mapping in mountainous terrain. Eng Geol 32(4):269-77

Anbalagan R, Kumar R, Lakshmanan K, Parida S, Neethu S (2015) Landslide hazard zonation mapping using frequency ratio and fuzzy logic approach, a case study of Lachung Valley, Sikkim. Geoenviron Disasters 2(1). https://doi.org/10. 1186/s40677-014-0009-y

Angeli MG, Pasuto A, Silvano S (2000) A critical review of landslide monitoring experiences. Eng Geol 55:133-147

Atkinson PM, Massari R (1998) Generalised linear modelling of susceptibility to landsliding in the central Apennines, Italy. Comput Geosci 24(4):373-385

Ayalew L, Yamagishi H (2005) The application of GIS-based logistic regression for landslide susceptibility mapping in the Kakuda-Yahiko Mountains, Central Japan. Geomorphology 65:15-31

Ayalew L, Yamagishi H, Ugawa N (2004) Landslide susceptibility mapping using GIS-based weighted linear combination, the case in Tsugawa area of Agano River, Niigata prefecture, Japan. Landslides 1:73-81

Ayele S, Raghuvanshi TK, Kala PM (2014) Application of remote sensing and GIS for landslide disaster management-a case from Abay gorge, GohatsionDejen section, Ethiopia. In: Singh M, Singh RB, Hassan MI (eds) Landscape ecology and water management, proceedings of international geographical union (IGU) Rohtak conference. Advances in Geographical and Environmental Science Springer, Japan, pp 15-32

Ayenew T, Barbieri G (2005) Inventory of landslides and susceptibility mapping in the Dessie area, northern Ethiopia. Eng Geol 77:1-15

Bachri S, Shresta RP (2010) Landslide hazard assessment using analytic hierarchy processing (AHP) and geographic information system in Kaligesing mountain area of Central Java Province Indonesia. In: Proceeding 5th Annual International Workshop \& Expo on Sumatra Tsunami Disaster \& Recovery, pp 107-12

Balasubramani K, Kumaraswamy K (2013) Application of geospatial technology and information value technique in landslide Hazard zonation mapping: a case study of Giri Valley, Himachal Pradesh. Disaster Adv 6(1):38-47

Ballabio C, Sterlacchini S (2012) Support vector Machines for Landslide Susceptibility Mapping: the Staffora River basin case study, Italy. Math Geosci 44(1):47-70

Basma AA, Kallas N (2004) Modeling soil collapse by artificial neural networks. Geotech Geol Eng 22:427-38

Baum RL, Savage WZ, Godt JW (2002) TRIGRS; a Fortran program for transient rainfall infiltration and grid-based regional slope-stability analysis. Open-file report 02-424

Bera A, Mukhopadhyay BP, Das D (2019) Landslide hazard zonation mapping using multi-criteria analysis with the help of GIS techniques: a case study from eastern Himalayas, Namchi, South Sikkim. Nat Hazards 96(2):935-959

Bisson M, Spinetti C, Sulpizio R (2014) Volcaniclastic flow hazard zonation in the sub-Apennine Vesuvian area using GIS and remote sensing. Geosphere 10(6): 1419-31

Bommer JJ, Rodri'guez CE (2002) Earthquake-induced landslides in Central America. Eng Geol 63:189-220
Bonham-Carter GF (1994) Geographic information systems for geoscientists: modelling with GIS. Computer methamphetamine geos, vol. 13. Pergamon, New York, p 398

Brenning A (2005) Spatial prediction models for landslide hazards: review, comparison and evaluation. Nat Hazards Earth Syst Sci 5(6):853-62

Carrara A, Cardinali M, Detti R, Guzzetti F, Pasqui V, Reichenbach P (1991) GIS techniques and statistical models in evaluating landslide hazard. Earth Surf Process Land 16(5):427-45

Carrara A, Cardinali M, Guzzetti F (1992) Uncertainty in assessing landslide hazard and risk. ITC J 2:172-83

Carrara A, Cardinali M, Guzzetti F, Reichenbach P (1995) GIS technology in mapping landslide hazard. In: Carrara A, Guzzetti F (eds) Geographical Information System in Assessing Natural Hazard. Kluwer Academic Publisher, Netherlands, pp 135-75

Casagli N, Catani F, Puglisi C, Delmonaco G, Ermini L, Margottini C (2004) An inventory-based approach to landslide susceptibility assessment and its application to the Virginio River Basin, Italy. Environ Eng Geosci 3:203-16

CEOS (2001) The use of earth observing satellites for hazard support: assessment and scenarios. CEOS report. NOAA, USA http://ceos.esa.int/plenary16/papers/plenary16 doc14_dmsg_final/final_report/DMSG_final.html, Last accessed 19 July 2014

Chacón J, Irigaray C, Fernandez T, El Hamdouni R (2006) Engineering geology maps: landslides and geographical information systems. Bull Eng Geol Environ 65(4):341-411

Chelli A, Segadelli S, Vescovi P, Tellini C (2015) Large-scale geomorphological mapping as a tool to detect structural features: the case of Mt. Prinzera ophiolite rock mass (northern Apennines, Italy). J Maps 12(5):770-776

Chen Z, Wang J (2007) Landslide hazard mapping using logistic regression model in Mackenzie Valley, Canada. Nat Hazards 42(1):75-89

Chimidi G, Raghuvanshi TK, Suryabhagavan KV (2017) Landslide hazard evaluation and zonation in and around Gimbi town, western Ethiopia - a GIS-based statistical approach. Appl Geomat (Springer) 9(4):219-236

Chowdhury M, Sadek AW (2012) Advantages and limitations of artificial intelligence. Artificial intelligence applications to critical transportation issues, 6, transportation research circular E-C168

Chung CF, Fabbri AG (1995) Multivariate regression analysis for landslide hazard zonation. In: Carrara A, Guzzetti FŽ (eds) Geographical Information Systems in assessing Natural Hazards. Kluwer Academic Publisher, Dordrecht, pp 107-142

Corominas J, van Westen CJ, Frattini P. Cascini L, Malet JP, Fotopoulou S, Catani F, van den Eeckhaut M, Mavrouli OC, Agliardi F, Pitilakis K, Winter MG, Pastor M, Ferlisi S, Tofani V, Hervás J, Smith JT (2014) Recommendations for the quantitative analysis of landslide risk: bull Eng. Geol Environ 73(2):209-63

Cortes C, Vapnik V (1995) Support-vector networks. Mach Learn 20(3):273-97

Crozier MJ, Glade T (2005) Landslide hazard and risk: issues, concepts, and approach. In: Glade T, Anderson M, Crozier M (eds) Landslide Hazard and risk. Wiley, Chichester, pp 1-40

Cruden DM, Varnes DJ (1996) Landslide types and processes. In: Turner AT, Schuster RL (eds) Landslides-investigation and mitigation. Transportation Research Board special report no, vol 247. National Academy Press, Washington, DC, pp 36-75

Dahal RK, Hasegawa S, Masuda T, Yamanaka M (2006) Roadside slope failures in Nepal during torrential rainfall and their mitigation. Disaster Mitigation of Debris Flows, Slope Failures and Landslides, pp 503-14

Dai FC, Lee CF (2001) Terrain-based mapping of landslide susceptibility using a geographical information system: a case study. Can Geotech J 38:911-23

Dai FC, Lee CF (2002) Landslide characteristics and slope instability modeling using GIS, Lantau Island, Hong Kong. Geomorphology 42:213-28

Dai FC, Lee CF, Li J, Xu ZW (2001) Assessment of landslide susceptibility on the natural terrain of Lantau Island, Hong Kong. Environ Geol 40:381-91

Dai FC, Lee CF, Ngai YY (2002) Landslide risk assessment and management: an overview. Eng Geol 64:65-87

Delmonaco G, Margottini C, Spizzichino D (2013) Rock-Fall Hazard assessment in the Siq of Petra, Jordan. In: Landslide Science and Practice, pp 441-49

Dietrich EW, Reiss R, Hsu M-L, Montgomery DR (1995) A process-based model for colluvial soil depth and shallow landsliding using digital elevation data. HydrologicalProcess 9:383-400

Đurić U, Marjanović M, Radić Z, Abolmasov B (2019) Machine learning based landslide assessment of the Belgrade metropolitan area: pixel resolution effects and a cross-scaling concept. Eng Geol 256:23-38

Ercanoglu M (2005) Landslide susceptibility assessment of SE Bartin (West Black Sea region, Turkey) by artificial neural networks. Nat Hazards Earth Syst Sci 5(6):979-92 
Erener A, Duzgun H (2012) Landslide susceptibility assessment: what are the effects of mapping unit and mapping method? Environ Earth Sci 66(3):859-77

Erener A, Mutlu A, Sebnem Düzgün H (2016) A comparative study for landslide susceptibility mapping using GIS-based multi-criteria decision analysis (MCDA), logistic regression (LR) and association rule mining (ARM). Eng Geol 203:45-55

Ermias B, Raghuvanshi TK, Abebe B (2017) Landslide Hazard zonation (LHZ) around Alemketema town, north Showa zone, Central Ethiopia - a GIS based expert evaluation approach. Int Jr Earth Sci Engg 10(1):33-44

Fall M, Azzam R, Noubactep C (2006) A multi-method approach to study the stability of natural slopes and landslide susceptibility mapping. Eng Geol 82: 241-63

Feizizadeh B, Blaschke T (2012). Comparing GIS-Multicriteria Decision Analysis for landslide susceptibility mapping for the lake basin, Iran. 2012 IEEE International Geoscience and Remote Sensing Symposium. https://doi.org/ 10.1109/igarss.2012.6352388

Feizizadeh B, Jankowski P, Blaschke T (2014) A GIS based spatially-explicit sensitivity and uncertainty analysis approach for multi-criteria decision analysis. Comput Geosci 64:81-95

Felicísimo ÁM, Cuartero A, Remondo J, Quirós E (2012) Mapping landslide susceptibility with logistic regression, multiple adaptive regression splines, classification and regression trees, and maximum entropy methods: a comparative study. Landslides 10(2):175-89

Fell R, Corominas J, Bonnard C, Cascini L, Leroi E, Savage WZ (2008) Guidelines for landslide susceptibility, hazard and risk zoning for land use planning, on behalf of the JTC-1 joint technical committee on Landslides and engineered slopes. Eng Geol 102:85-98

Fell R, Whitt G, Miner A, Flentje PN (2007) Guidelines for landslide susceptibility, hazard and risk zoning for land use planning. Aust Geomechanics J 42(1):13-36

Garrett J (1994) Where and why artificial neural networks are applicable in civil engineering. J Comput Civ Eng 8:129-30

GEO-SLOPE (2011) SLOPE/W. GEO-SLOPE International, Calgary http://www.geoslope.com

Girma F, Raghuvanshi TK, Ayenew T, Hailemariam T (2015) Landslide hazard zonation in Ada Berga district, Central Ethiopia - a GIS based statistical approach. J Geom 9(i):25-38

Gitirana G Jr, Santos MA, Fredlund MD (2008) Three-dimensional slope stability model using finite element stress analysis. GeoCongress 2008. Available at. https://doi.org/10.1061/40971(310)24

Goetz JN, Brenning A, Petschko H, Leopold P (2015) Evaluating machine learning and statistical prediction techniques for landslide susceptibility modeling. Comput Geosci 81:1-11

Gómez H, Kavzoglu T (2005) Assessment of shallow landslide susceptibility using artificial neural networks in Jabonosa River basin, Venezuela. Eng Geol 78(1-2):11-27

Goodman RE (1989) Introduction to rock mechanics, University of California at Berkeley, pp. 562

Gorsevski PV, Gessler PE, Foltz RB (2000) Spatial Prediction of Landslide Hazard Using Logistic Regression and GIS. In: Proceeding 4th International Conference on Integrating GIS and Environmental Modeling (GIS/EM4): Problems, Prospects and Research Needs, Banff, Alberta, Canada. J Environ Manage 57(4):296 https://doi.org/10.1016/s0301-4797(99)90317-1

Gorsevski PV, Gessler PE, Foltz RB, Elliot WJ (2006a) Spatial prediction of landslide Hazard using logistic regression and ROC analysis. Trans GIS 10(3):395-415

Gorsevski PV, Gessler PE, Jankowski P (2003) Integrating a fuzzy k-means classification and a Bayesian approach for spatial prediction of landslide hazard. J Geographical Syst 5:223-51

Gorsevski PV, Jankowski P (2010) An optimized solution of multi-criteria evaluation analysis of landslide susceptibility using fuzzy sets and Kalman filter. Comput Geosci 36(8):1005-20

Gorsevski PV, Jankowski P, Gessler PE (2006b) An heuristic approach for mapping landslide hazard by integrating fuzzy logic with analytic hierarchy process. Control Cybern 35(1):121-46

Guzzetti F, Cardinali M, Reichenbach P, Carrara A (2000) Comparing landslide maps: a case study in the upper Tiber River basin, Central Italy. Environ Manag 25(3):247-363

Guzzetti F, Carrara A, Cardinali M, Reichenbach P (1999) Landslide hazard evaluation: a review of current techniques and their application in a multiscale study, Central Italy. Geomorphology 31:181-216

Guzzetti F, Galli M, Reichenbach P, Ardizzone F, Cardinali M (2006) Landslide hazard assessment in the Collazzone area, Umbria, Central Italy. Nat Hazards Earth Syst Sci 6:115-31
Guzzetti F, Mondini AC, Cardinali M, Fiorucci F, Santangelo M, Chang KT (2012) Landslide inventory maps: new tools for an old problem. Earth-Sci Rev 112(1):42-66

Guzzetti F, Reichenbach P, Cardinali M, Galli M, Ardizzone F (2005b) Probabilistic landslide hazard assessment at the basin scale. Geomorphology 72(1-4):272-99

Guzzetti F, Stark CP, Salvati P (2005a) Evaluation of flood and landslide risk to the population of Italy. Environ Manag 36(1):15-36

Hack HRGK (1998) Slope stability probability classification, vol. 43. ITC Delft Publication, Netherlands, Enschede, p 273

Hamza T, Raghuvanshi TK (2017) GIS based Landslide Hazard Evaluation and Zonation A case from Jeldu District, Central Ethiopia. J King Saud Univ Sci 29(2):151-65

Han L, Zhang J, Zhang Y, Lang Q (2019) Applying a series and parallel model and a Bayesian networks model to produce disaster chain susceptibility maps in the Changbai Mountain area, China. Water 11(10):2144

Haykin S (1999) Neural networks: a Comprehensive Foundation, second edition. Prentice Hall, New Jersey, p 818

He S, Pan P, Dai L, Wang H, Liu J (2012) Application of kernel-based Fisher discriminant analysis to map landslide susceptibility in the Qinggan River delta, Three Gorges, China. Geomorph 171-172:30-41. https://doi.org/10. 1016/j.geomorph.2012.04.024

Hoek E, Bray JW (1981) Rock slope engineering (Revised Third Edition). Institute of Mining and Metallurgy, London, p 358

Huabin W, Gangjun L, Gonghui W (2005) GIS-based landslide hazard assessment: an overview. Prog Phys Geogr 29(4):548-67

Hungr O, Rawlings G (1995) Assessment of terrain hazards for planning purposes: Cheekye Fan, British Columbia. Proceedings of 48. Canadian Geotechnical Conference, Vancouver, pp 25-27 September 1995, 1: 509-17

Hutchinson JN (1995) Landslide hazard assessment: keynote paper. In: Bell DH (ed) Landslides, A.A, Proceedings of the Sixth International Symposium on Landslides. Balkema, Rotterdam, pp 1805-41

IAEG, Commission on Landslides (1990) Suggested nomenclature for landslides. Bull. Int. Assoc. Eng Geol 41:13-16

Ibsen M-L, Brunsden D (1996) The nature, use and problems of historical archives for the temporal occurrence of landslides, with specific reference to the south coast of Britain, Ventnor, Isle of Wight. Geomorphology 15(3-4):241-258

Intarawichian N, Dasananda S (2010) Analytical hierarchy process for landslide susceptibility mapping in lower Mae Chem watershed, northern Thailand. Suranaree J Sci Technol 17(3):277-92

Jaboyedoff M, Oppikofer T, Abellán A, Derron MH, Loye A, Metzger R, Pedrazzini A (2012) Use of LIDAR in landslide investigations: a review. Nat Hazards 61(1):5-28

Jade S, Sarkar S (1993) Statistical models for slope instability classification. Eng Geol 36(1-2):91-98

Jongmans D, Garambois S (2007) Geophysical investigation of landslides: a review. Bull Soc Geol Fr 178:101-12

Kanungo DP, Arora MK, Sarkar S, Gupta RP (2006) A comparative study of conventional, ANN black box, fuzzy and combined neural and fuzzy weighting procedures for landslide susceptibility zonation in Darjeeling Himalayas. Eng Geol 85:347-66

Kanungo DP, Arora MK, Sarkar S, Gupta RP (2009) Landslide susceptibility zonation (LSZ) mapping: a review. J South Asia Disaster Stud 2:81-105

Karaman K, Ercikdi B, Kesimal A (2013) The assessment of slope stability and rock excavatability in a limestone quarry. Earth Sci Res SJ 17(2):169-81

Kavzoglu T, Colkesen I (2009) A kernel functions analysis for support vector machines for land cover classification. Int J Appl Earth Obs Geoinf 11(5):352-59

Kavzoglu T, Colkesen I, Sahin EK (2018) Machine learning techniques in landslide susceptibility mapping: a survey and a case study. Adv Nat Technol Hazards Res 283-301. https://doi.org/10.1007/978-3-319-77377-3_13

Kavzoglu T, Kutlug Sahin E, Colkesen I (2014) An assessment of multivariate and bivariate approaches in landslide susceptibility mapping: a case study of Duzkoy district. Nat Hazards 76(1):471-96

Kavzoglu T, Sahin EK, Colkesen I (2013) Landslide susceptibility mapping using GIS-based multi-criteria decision analysis, support vector machines, and logistic regression. Landslides 11(3):425-39

Keefer DV (2000) Statistical analysis of an earthquake-induced landslide distribution - the 1989 Loma Prieta, California event. Eng Geol 58:231-249

Kulatilake PHSW, Wang L, Tang H, Liang Y (2011) Evaluation of rock slope stability for Yujian River dam site by kinematic and block theory analyses. Comput Geotech 38:846-60

Kuriakose SL (2010) Physically-based dynamic modelling of the effect of land use changes on shallow landslide initiation in the Western Ghats of Kerala, India. Ph.D. thesis. University of Utrecht, Utrecht ISBN 978-90-6164-298-5 
Lan HX, Zhou CH, Wang LJ, Zhang HY, Li RH (2004) Landslide hazard spatial analysis and prediction using GIS in the Xiaojiang watershed, Yunnan, China. Eng Geol 76:109-28

Lari S, Frattini P, Crosta GB (2014) A probabilistic approach for landslide hazard analysis. Eng Geology 182:3-14

Lee CT (2015) Review and perspectives on methodology for landslide hazard analysis: 10thAsian regional conference of IAEG (2015)

Lee CT, Huang CC, Lee JF, Pan KL, Lin ML, Dong JJ (2008) Statistical approach to storm event-induced landslides susceptibility. Nat Hazard Earth Syst Sci 8(4): $941-60$

Lee S (2005) Application of logistic regression model and its validation for landslide susceptibility mapping using GIS and remote sensing data. Int J Remote Sens 26(7):1477-91

Lee S (2007) Application and verification of fuzzy algebraic operators to landslide susceptibility mapping. Environ Geol 50:847-55

Lee S, Min K (2001) Statistical analysis of landslide susceptibility at Yongin. Korean Environ Geol 40:1095-113. https://doi.org/10.1007/s002540100310

Lee S, Ryu JH, Min KD, Won JS (2003) Landslide susceptibility analysis using GIS and artificial neural network. Earth Surf Process Landforms 27:1361-76

Lee S, Ryu JH, Won JS, Park HJ (2004) Determination and application of the weights for landslide susceptibility mapping using an artificial neural network. Eng Geol 71(3-4):289-302

Leroi E (1997) Landslide risk mapping: problems, limitation and developments. In: Cruden F (ed) Landslide Risk Assessment. Balkema, Rotterdam, pp 239-250

Lin ML, Tung CC (2003) A GIS-based potential analysis of the Landslides induced by the chi-chi earthquake. Eng Geol 71:63-77

Lipmann RP (1987) An introduction to computing with neural nets. IEEE Assp magazine 4:4-22

Liu Y-C, Chen C-S (2007) A new approach for application of rock mass classification on rock slope stability assessment. Eng Geol 89(1-2):129-43

Malamud BD, Turcotte DL, Guzzetti F, Reichenbach P (2004) Landslide inventories and their statistical properties. Earth SurfProcess Landforms 29:687-711

Mandaglio MC, Moraci N, Rosone M, AiròFarulla C (2016) Experimental study of a naturally weathered stiff clay. Can Geotech J 53(12):2047-57

Menard S (1995) Applied logistic regression analysis. Sage University paper series on quantitative applications in social sciences, 106. Thousand Oaks, California, p 98

Mengistu F, Suryabhagavan KV, Raghuvanshi TK, Lewi E (2019) Landslide Hazard zonation and slope instability assessment using optical and InSAR data: a case study from Gidole town and its surrounding areas, southern Ethiopia. Remote Sensing of Land 3(1):1-14

Meten M, Bhandary NP, Yatabe R (2015) Application of GIS-based fuzzy logic and rock engineering system (RES) approaches for landslide susceptibility mapping in Selelkula area of the lower Jema River gorge, Central Ethiopia. Environ Earth Sci 74(4):3395-3416

Metternicht G, Hurni L, Gogu R (2005) Remote sensing of landslides: an analysis of the potential contribution to geo-spatial systems for hazard assessment in mountainous environments. Remote Sens Environ 98(2-3):284-303

Michoud C, Derron MH, Hortin P, Jaboyedoff M, Baillifard FJ, Loye A, Nicolet P, Pedrazzini A, Queyrel A (2012) Rockfall hazard and risk assessments along roads at a regional scale: example in Swiss Alps. Nat Hazards Earth Syst Sci 12:615-29

Mohammady M, Pourghasemi HR, Pradhan B (2012) Landslide susceptibility mapping at Golestan Province, Iran: a comparison between frequency ratio, DempsterShafer, and weights-of-evidence models. J Asian Eart Scie 61:221-36

Moung-Jin L, Won-Kyong S, Joong-Sun W, Inhye P, Saro L (2014) Spatial and temporal change in landslide hazard by future climate change scenarios using probabilistic-based frequency ratio model. Geocarto Int 29(6):639-62

Nandi A, Shakoor A (2009) A GIS based landslide susceptibility evaluation using bivariate and multivariate statistical analyses. Eng Geol 110:11-20

Neaupane K, Achet S (2004) Use of backpropagation neural network for landslide monitoring: a case study in the higher Himalaya. Eng Geol 74(3-4):213-26

Nefeslioglu HA, Gokceoglu C, Sonmez H (2008) An assessment on the use of logistic regression and artificial neural networks with different sampling strategies for the preparation of landslide susceptibility maps. Eng Geol 97(3-4):171-91. https://doi.org/10.1016/j.enggeo.2008.01.004

Nossin JJ (1989) Aerospace survey of natural hazards. ITC journal, 3-4: 183-88. On rock slope stability assessment. Eng Geo 89:129-43

Pachauri AK, Pant M (1992) Landslide hazard mapping based on geological attributes. Eng Geol 32:81-100

Pack RT, Tarboton DG, Goodwin CN (1998) The Sinmap approach to terrain stability mapping. In: Proceedings 8th Congress of the International
Association of Engineering Geology, Vancouver, A A Balkema. Eng Geol Nat Hazards 2:1157-66

Pan X, Nakamura H, Nozaki T, Huang X (2008) A GIS-based landslide hazard assessment by multivariate analysis Landslides. J Jpn Landslide Soc 45(3): 187-95

Paola JD, Schowengerdt RA (1995) A review and analysis of backpropagation neural networks for classification of remotely-sensed multi-spectral imagery. Int J Remote Sens 16(16):3033-58

Pardeshi SD, Autade SE, Pardeshi SS (2013) Landslide hazard assessment: recent trends and techniques. Springer Plus 2:1-11

Parise M, Jibson RW (2000) A seismic landslide susceptibility rating of geologic units based on analysis of characteristics of landslides triggered by the 17 January, 1994 Northridge, California earthquake. Eng Geol 58:251-70

Pawley S, Hartman G, Chao D (2017) Landslide susceptibility modelling of Alberta, Canada: comparative results from multiple statistical and machinelearning prediction method. https://doi.org/10.1130/abs/2017am-304456

Pradhan B, Lee S (2009) Landslide risk analysis using artificial neural network model focussing on different training sites. Int J PhysSci 4:001-015

Pradhan B, Lee S (2010) Landslide susceptibility assessment and factor effect analysis: backpropagation artificial neural networks and their comparison with frequency ratio and bivariate logistic regression modelling. Environ ModellSoftw 25:747-59

Raghuvanshi TK (2019) Governing factors influence on rock slope stability Statistical analysis for plane mode of failure. J King Saud Univ - Sci 31(4): 1254-63. https://doi.org/10.1016/j.jksus.2019.01.002

Raghuvanshi TK, Ibrahim J, Ayalew D (2014a) Slope stability susceptibility evaluation parameter (SSEP) rating scheme-an approach for landslide hazard zonation. J Afr Earth Sci 99:595-612

Raghuvanshi TK, Kala PM, Singh M (2014b) Landslide Disaster Management and Reduction- An approach through Remote Sensing and GIS. In: Singh M, Singh RB, Hassan Ml (eds) Landscape Ecology and Water Management, Proceedings of International Geographical Union (IGU) Rohtak Conference, Vol-2, Advances in Geographical and Environmental Sciences. Springer, Japan, pp 33-40

Raghuvanshi TK, Negassa L, Kala PM (2015) GIS based grid overlay method versus modeling approach - a comparative study for landslide Hazard zonation $(\mathrm{LHZ})$ in Meta Robi District of west Showa zone in Ethiopia. Egypt J Remote Sens Space Sci 18:235-50

Razifard M, Shoaei G, Zare M (2018) Application of fuzzy logic in the preparation of hazard maps of landslides triggered by the twin Ahar-Varzeghan earthquakes (2012). Bull Eng Geol Environ 78(1):223-45

Reichenbach P, Rossi M, Malamu BD, Mihir M, Guzzetti F (2018) A review of statistically-based landslide susceptibility models. Ear Sci Revs 180:60-91

Ripley B (1996) Pattern recognition and neural networks. Cambridge Univ. Press, Cambridge, p 354

Romana M (1985) New adjustment ratings for application of Bieniawski classification to slope, International Symposium on Role Rock Mechanics Zacatecas, pp 49-53

Ross TJ (2010) Fuzzy Logic with Engineering Applications. Available at:. https:// doi.org/10.1002/9781119994374

Ruff M, Czurda K (2008) Landslide susceptibility analysis with a heuristic approach in the eastern Alps (Vorarlberg, Austria). Geomorphology 94(3-4):314-324

Saaty T (2008) Decision making with the analytical hierarchy process. Int J Services Sci 1(1):83-98

Saaty TL, Vargas LG (2006) Decision making with the analytic network process: economic, political, social and technological applications with benefits, Opportunities, Costs and Risks. Springer, New York

Safaei M, Omar H, Huat BK, Yousof ZBM, Ghiasi V (2011) Deterministic rainfall induced landslide approaches, advantage and limitation. Electron J Geotech Eng 16:1619-50

Sarkar S, Kanungo DP, Mehrotra GS (1995) Landslide hazard zonation: a case study in Garhwal Himalaya, India. Moun Res Dev 15(4):301-309

Schicker R, Moon V (2012) Comparison of bivariate and multivariate statistical approaches in landslide susceptibility mapping at a regional scale. Geomorphology 161:40-57

Selby MJ (1980) A rock mass strength classification for geomorphic purposes: with tests from Antarctica and New Zealand. Z Geomorphol 24:31-51

Sharma S, Raghuvanshi T, Anbalagan R (1995) Plane failure analysis of rock slopes. Geot Geol Eng 13:105-11

Simoni S, Zanotti F, Bertoldi G, Rigon R (2008) Modelling the probability of occurrence of shallow landslides and channelized debris flows using GEOtop-FS. Hydrol Process 22(4):532-45 
Soeters R, Van Westen CJ (1996) Slope instability recognition analysis and zonation. In: Turner KT, Schuster RL (eds) Landslides: investigation and mitigation. Transportation Research Board National Research Council, Special Report No 247, Washington, DC, pp 129-77

Sreedevi N, Yarrakula K (2016) Different techniques for landslide zonation mapping and landslide assessment: a review. Indian J Sci Technol 9(47) https://doi.org/10.17485/ijst/2015/v8i1/106518

Stead D, Eberhardt E, Coggan JS (2006) Developments in the characterization of complex rock slope deformation and failure using numerical modelling techniques. Eng Geol 83(1-3):217-35

Steger S, Brenning A, Bell R, Glade T (2016) The propagation of inventory-based positional errors into statistical landslide susceptibility models. Nat Hazards Earth Syst Sci 16(12);2729-45

Straub D, Schubert M (2008) Modeling and managing uncertainties in rock-fall hazards. Georisk 2(1):1-15

Süzen ML, Doyuran V (2004) Data driven bivariate landslide susceptibility assessment using geographical information systems: method and application to Asarsuyu catchment, Turkey. Eng Geol 71:303-21

Swets J (1988) Measuring the accuracy of diagnostic systems. Science 240(4857): 1285-93

Tang H, Yong R, Ez Eldin MAM (2016) Stability analysis of stratified rock slopes with spatially variable strength parameters: the case of Qianjiangping landslide. Bull Eng Geol Environ. https://doi.org/10.1007/s10064-016-0876-4

Thiebes B, Glade T, Bell R (2012) Landslide analysis and integrative early warninglocal and regional case studies. In: Eberhardt $\mathrm{E}$ (ed) Landslides and engineered slopes: protecting society through improved understanding. Taylor\& Francis Group, London, pp 1915-21

Tien Bui D, Tuan TA, Klempe H, Pradhan B, Revhaug I (2015) Spatial prediction models for shallow landslide hazards: a comparative assessment of the efficacy of support vector machines, artificial neural networks, kernel logistic regression, and logistic model tree. Landslides 13(2):361-78

Turner AK, Schuster RL (1996) Landslides: investigation and mitigation, Transportation Research Board Special Report 247. National Research Council, Washington, D.C, p 673

Turrini CT, Visintainer P (1998) Proposal of a method to define areas of landslide hazard and application to an area of the Dolomites, Italy. Eng Geol 50:255-65

Van Den Eeckhaut M, Vanwalleghem T, Poesen J, Govers G, Verstraeten G, Vandekerckhove $L$ (2006) Prediction of landslide susceptibility using rare events logistic regression: a case-study in the Flemish Ardennes (Belgium). Geomorphology 76(3-4):392-410

Van Westen CJ (1993) Application of Geographic Information Systems to Landslide Hazard Zonation. ITC Publication, vol. 15. International Institute for Aerospace and Earth Resources Survey, Enschede, p 245

van Westen CJ (1994) In: Price MF, Heywood DIŽ (eds) GIS in landslide hazard zonation: a review with examples from the Colombian Andes. Taylor and Francis, London, pp 135-65

Van Westen CJ, Rengers N, Soeters R (2003) Use of geomorphological information in indirect landslide susceptibility assessment. Nat Hazards 30: 399-419

Van Westen CJ, Rengers N, Terlien MTJ, Soeters R (1997) Prediction of the occurrence of slope instability phenomenal through GIS-based hazard zonation. Geol Rundsch 86(2):404-14

Van Westen CJ, van Asch TWJ, Soeters R (2005) Landslide hazard and risk zonation-why is it still so difficult? Bull Eng Geol Environ 65(2):167-184

Van Western CJ (2002) Use of Weights of Evidence Modeling for Landslide Susceptibility Mapping, p 21

Vapnik VN (1999) The nature of statistical learning theory, 2nd edn. Springer, New York

Varnes D, IAEG (1984) Landslide hazard zonation: a review of principles and practice. U N Sci Cult Organ, Paris, pp 1-6

Varnes DJ (1996) Landslide types and processes. In: Turner AK, Schuster RL (eds) Landslides: investigation and mitigation, Transportation Research Board special report 247. National Academy Press, National Research Council, Washington, D.C

Verstappen HT (1983) Applied geomorphology: Geomorphological survey for environmental development, vol xi. Elsevier Scientific Publishing Co, Amsterdam, p 437

Wang X, Niu R (2009) Spatial forecast of landslides in three gorges based on spatial data mining. Sensors 9:2035-61

Wu LZ, Huang RQ, Xu Q, Zhang LM, Li HL (2015) Analysis of physical testing of rainfall-induced soil slope failures. Environ Earth Sci 73(12):8519-31
Yagi H (2003) Development of assessment method for landslide hazardness by AHP. In: Abstract volume of the 42nd annual meeting of the Japan Landslide Society, pp 209-12

Yalcin A (2008) GIS-based landslide susceptibility mapping using analytical hierarchy process and bivariate statistics in Ardesen (Turkey): comparisons of results and confirmations. Catena 72:1-12

Yesilnacar E, Topal T (2005) Landslide susceptibility mapping: a comparison of logistic regression and neural networks methods in a moderate scale study, Hendek region (Turkey). Eng Geol 79:251-66

Yin KL, Yan TZ (1988) Statistical prediction model for slope instability of metamorphosed rocks. 5th international symposium on Landslides. Lausanne 2:1269-72

Zadeh LA (1978) Fuzzy sets as a basis for a theory of possibility. Fuzzy Sets Syst 1: $3-28$

ZainAlabideen K, Helal M (2016) Determination of the safe orientation and dip of a rock slope in an open pit mine in Syria using kinematic analysis. Al-Nahrain Univ College Eng J 91(1):33-45

Zell A, Mache N, Hüttel M, Vogt M (1993) Simulation Neuronaler Netze auf Massiv Parallelen Rechnern. Informatik aktuell 495-502. https://doi.org/10.1007/9783-642-78486-6_88

Zêzere $J \mathrm{~L}$ et al (2004) Integration of spatial and temporal data for the definition of different landslide hazard scenarios in the area north of Lisbon (Portugal). Natural Hazards and Earth System Science 4(1):133-46

Zhou C, Lee C, Li J, Xu Z (2002) On the spatial relationship between landslides and causative factors on Lantau Island, Hong Kong. Geomorphology 43:197-207

Zimmermann H-J (1996) Fuzzy sets and expert systems. Fuzzy Set Theory-and Its Applications, pp 173-201

\section{Publisher's Note}

Springer Nature remains neutral with regard to jurisdictional claims in published maps and institutional affiliations.

\section{Submit your manuscript to a SpringerOpen ${ }^{\circ}$ journal and benefit from:}

- Convenient online submission

- Rigorous peer review

- Open access: articles freely available online

- High visibility within the field

- Retaining the copyright to your article

Submit your next manuscript at $>$ springeropen.com 